\title{
Mapping high-resolution basal topography of West Antarctica from radar data using non-stationary multiple-point geostatistics (MPS- BedMappingV1)
}

5

\author{
Zhen Yin ${ }^{1}$, Chen Zuo ${ }^{2}$, Emma J. MacKie ${ }^{3}$ and Jef Caers ${ }^{1}$
}

${ }^{1}$ Department of Geological Sciences, Stanford University, California 94305, USA

${ }^{2}$ Department of Big Data Management and Application, Chang'an University, Xi'an, China

${ }^{3}$ Department of Geophysics, Stanford University, California 94305, USA

Correspondence to: Zhen Yin: yinzhen@stanford.edu;

10 Other contacts: Chen Zuo chenzuo789@outlook.com; Emma J. Mackie mackie3@stanford.edu; Jef Caers: jcaers@stanford.edu

\begin{abstract}
The subglacial bed topography is critical for modeling the evolution of Thwaites Glacier in the Amundsen Sea Embayment (ASE), where rapid ice loss threatens the stability of the West Antarctic Ice Sheet. However, mapping of subglacial topography is subject to high uncertainty. This is mainly because the bed topography is measured by airborne ice-penetrating radar along flight lines with large gaps up to tens of kilometers. Deterministic interpolation approaches do not reflect such spatial uncertainty. While traditional geostatistical simulation can model such uncertainty, it may be difficult to apply because of the significant non-stationary spatial variation of topography over such large surface area. In this study, we develop a nonstationary multiple-point geostatistical approach to interpolate large areas with irregular geophysical data and apply it to model the spatial uncertainty of entire ASE basal topography. We collect 166 high-resolution topographic training images (TIs) to

20 train the gap-filling of radar data gaps, thereby simulating realistic topography maps. The TIs are extensively sampled from deglaciated regions in the Arctic as well as Antarctica. To address the non-stationarity in topographic modeling, we introduce a Bayesian framework that models the posterior distribution of non-stationary training images to the local modeling domain. Sampling from this distribution then provide candidate training images for local topographic modeling with uncertainty, constrained to radar flight line data. Compared to traditional MPS approaches without considering TI sampling, our approach demonstrates significant improvement in the topographic modeling quality and efficiency of the simulation algorithm. Finally, we simulate multiple realizations of high-resolution ASE topographic maps. We use the multiple realizations to investigate the impact of basal topography uncertainty on subglacial hydrological flow patterns.
\end{abstract}

\section{Introduction}

The topography beneath the Greenland and Antarctic ice sheets is essential for nearly every ice sheet investigation, including 30 modeling subglacial hydrology (MacKie et al., 2021), interpreting geologic conditions (Holschuh et al., 2020), estimating ice volume and sea level rise contributions (Fretwell et al., 2013), and ice sheet modeling for sea level rise projections (Le clec'h 
et al., 2019; Seroussi et al., 2017). The characterization of subglacial topography is particularly important for Thwaites Glacier in the Amundsen Sea Embayment, which is experiencing accelerating ice loss (Rignot et al., 2019) that could destabilize the West Antarctic Ice Sheet (Joughin et al., 2014). Subglacial topography is predominantly measured with airborne icepenetrating radar along flight lines separated by up to tens of km (Fretwell et al., 2013; Herzfeld et al., 1993). Large gaps in data remain, which are generally interpolated deterministically using methods such as kriging (Fretwell et al., 2013) or ice sheet model inversions (Huss and Farinotti, 2012; Morlighem et al., 2017, 2020). These approaches produce topography that is unrealistically smooth and provide limited morphological information. Furthermore, deterministically interpolated topography does not sample the uncertainty space, making it difficult to quantify uncertainty in ice sheet models with respect to topographic uncertainty.

These issues have previously been addressed with two-point geostatistical simulation, such as sequential Gaussian simulation (SGSIM) (MacKie et al., 2021). The objective of geostatistical simulation is to generate multiple realizations of phenomena that reproduce the spatial variability of observations, as modeled by variogram or spatial covariance and can be used to quantify uncertainty (e.g. Deutsch and Journel, 1998). Thwaites Glacier has previously been simulated by Goff et al. (2014), though only one realization was generated. Geostatistical simulation has also been applied in Antarctica and Greenland to quantify uncertainty in subglacial hydrology (MacKie et al., 2020, 2021; Zuo et al., 2020).

However, spatial variation over very large areas is inherently non-stationary. For example, The Greenland and Antarctic ice sheets are thousands of $\mathrm{km}$ across and contain a globally wide range of topographic and geologic settings. This means that the nature of spatial variation changes significantly and possibly in complex ways over the domain of interest. Traditional geostatistical ways of dealing with non-stationary data is through the modeling of trend functions (e.g. Pyrcz and White, 2015) or using covariates (e.g. Almeida and Journel, 1994; MacKie et al., 2021). However, such approaches typically model the variation in the mean (trend) or some degree of correlation (co-simulation). Another approach is using a non-stationary spatial covariance model (Schmidt and O'Hagan, 2003). Such approach becomes exceedingly difficult to apply over large areas because of the use of Markov chain Monte Carlo in its Bayesian inference. Regardless, all these approaches are limited in expressing non-stationary in terms of a mean or covariance function only.

The non-stationary bed topography is directly measured using high-resolution remote sensing data such as satellite images,

60 but only in deglaciated areas (Porter et al., 2018). Deglaciated topographic images reveal glaciated morphologies resembling the topography beneath the ice sheets (King et al., 2009; Margold et al., 2015; Spagnolo et al., 2017). They therefore bear significant information on the subglacial topography. Exposed topography has previously been used to perform deterministic interpolations (Clarke et al., 2009). However, satellite imagery of deglaciated topography has not been explored to stochastically simulate subglacial topography. 
Recent developments in multiple-point geostatistics (MPS) has shown great potentials in using high-resolution training images (e.g. satellite images) to fill remote sensing gaps (e.g. Gravey and Mariethoz, 2020; Mariethoz et al., 2012; Yin et al., 2017; Zakeri and Mariethoz, 2021; Zuo et al., 2020). MPS approaches use the training images (TIs) as explicit prior models to generate realistic topographical models and quantify spatial uncertainty. The simulation of non-stationary and morphologically complex topography can also be achieved with MPS (Hoffimann et al., 2017a, 2019; Mariethoz and Caers, 2014). Compared to alternative machine learning or deep learning approaches (Laloy et al., 2018; Mo et al., 2020), MPS has a flexible conditioning capability and can accommodate sparse and non-uniform sampling in space. It can generate multiple topographic model realizations conditioned to the radar line observations, without requiring a large amount of training data.

We review three categories of approaches to build non-stationary geospatial models using MPS. One simple way is to divide the non-stationary model simulation domain into several stationary zones, and then use different stationary TIs for each zone (Strebelle, 2002; Wu et al., 2008). Another way instead divides non-stationary TIs into small stationary zones. Then MPS then uses different divided TI patterns to fill different locations in the simulation domain (Honarkhah and Caers, 2012; Zhou et al., 2014). But the zonation in either the simulation domain or training images can make it difficult to maintain smooth transitions between the modeling patterns. Therefore, a third way is most commonly used. It incorporates spatially continuous non-stationary maps (named as "auxiliary variables") by ad-hoc weighting (Chugunova and Hu, 2008; Mariethoz et al., 2010a; Oriani et al., 2014; Zuo et al., 2020). Such auxiliary variables determine which TI patterns should fill which location in the simulation domain in a spatially smooth manner. The limitation is that the ad-hoc weights do not scale to the complexity of bed topography. The determination of weights is also subjective. More importantly, auxiliary variables are very difficult to obtain in subglacial topographic modeling. Another challenge in the non-stationary modeling is how to choose training images

85 (Tahmasebi, 2018). This is particularly important as the MPS modeling relies on the spatial information provided by the training images. Hoffimann et al. (2019) introduced an approach to generate time-series training images to model the spatial and temporal evolutions of geomorphology. A training image transitional model in time was proposed to reproduce the nonstationary geomorphologic evolutions. However, in subglacial topographic modelling, there are no available training images because subglacial topographic measurements are only made along flight lines. Satellite altimetry observations from deglaciated areas in the Arctic offer a potential source of training imagery. However, training images retrieved from the Arctic would be logically non-stationary due to the natural variability of the landscape. Furthermore, the Arctic provides a vast amount of deglaciated topographic data, which presents a significant computational burden on MPS simulation algorithms. We therefore will need a strategy to explicitly specify which training images or patterns should go where when filling the radar line gaps.

In this paper, we generalize a geospatial modeling framework to fill irregular geophysical data gaps in large areas. We will address the non-stationary topographic modeling by properly selecting non-stationary topographic training images using MPS. We first collect a large amount of topographic images to serve as the training images. These images are taken from the deglaciated areas in the Arctic and Antarctica. To assign the training images to local areas, we develop a probabilistic method 
100 for estimating the posterior distribution over the prior set of training images. The posterior distribution is conditioned (constrained) on the radar flight line data. The posterior TI probability will be calculated using kernel density estimation conditioned to the actual radar line observations. Such TI sampling scheme will avoid the use of auxiliary variables with arbitrary ad-hoc weightings. We will demonstrate our method using the entire Amundsen Sea Embayment in West Antarctica. This region has alternating areas of sparse and dense measurements with a variety of radar line spacings and orientations. We

105 show that the training image sampling process accommodates a range of data configurations. It will generate realistic nonstationary topographic realizations that reflect the subglacial topographic uncertainty in ASE. We use the topographic simulations to model subglacial hydrologic flow in order to investigate the impact of topographic uncertainty on hydrologic uncertainty.

\section{Radar data set $\&$ training images}

110 The topographic data for the ASE includes seafloor bathymetry measurements from the International Bathymetric Chart of the Southern Ocean (IBCSO) (Arndt et al., 2013), subaerial topography from the Reference Elevation Model of Antarctica (REMA) (Howat et al., 2019), and ice-penetrating radar measurements of subglacial topography (Blankenship et al., 2001; Gogineni, 2012; Holschuh et al., 2020; Holt et al., 2006; Vaughan et al., 2006; Young et al., 2016). The data is gridded at a 500-meter resolution (Figure 1). The swath bathymetry data (Arndt et al., 2013) and subglacial swath radar data (Holschuh et

115 al., 2020) (provide some training imagery. To have more extensive representations of the subglacial topography, we augment the available training data with deglaciated subaerial topography from the ArcticDEM (Porter et al., 2018). The Arctic and much of North America was formerly covered by the Laurentide and Cordilleran ice sheets and share morphological similarities with Antarctic subglacial topography (King et al., 2009; Margold et al., 2015). While the seafloor and subaerial topography may have experienced additional depositional processes after deglaciation, any topographic alterations are likely

120 minimal at a $500 \mathrm{~m}$ resolution. We sampled a total 166 candidate training images to capture a variety of geologic settings (Figure 2). Each training image has a size of $100 \times 100 \mathrm{~km}^{2}$. The training image data repository is publicly accessible from Zenodo repository (https://zenodo.org/record/5083715\#.YQT2JI5Kiiw, DOI 10.5281/zenodo.5083715) 


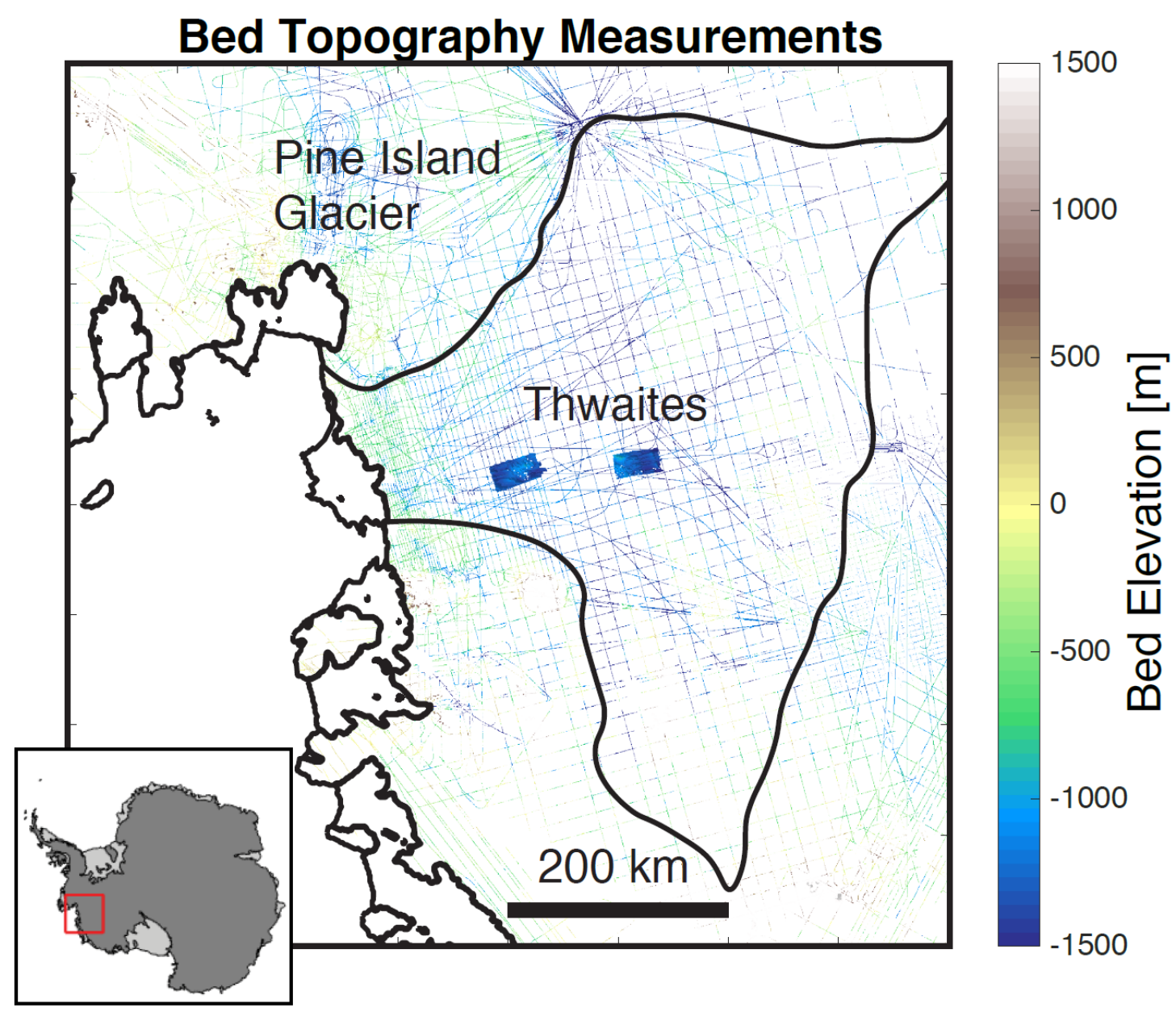

Figure 1. Radar line surveys of the Thwaites and Pine Island glaciers in the Amundsen Sea Embayment of West Antarctica. Black lines indicate boundaries for Thwaites Glacier, ice shelves, and the grounding line (the point where the ice detaches from the bed and achieves flotation). The topography patches in the center of Thwaites Glacier were measured using swath radar (Holschuh et al., 2020). 

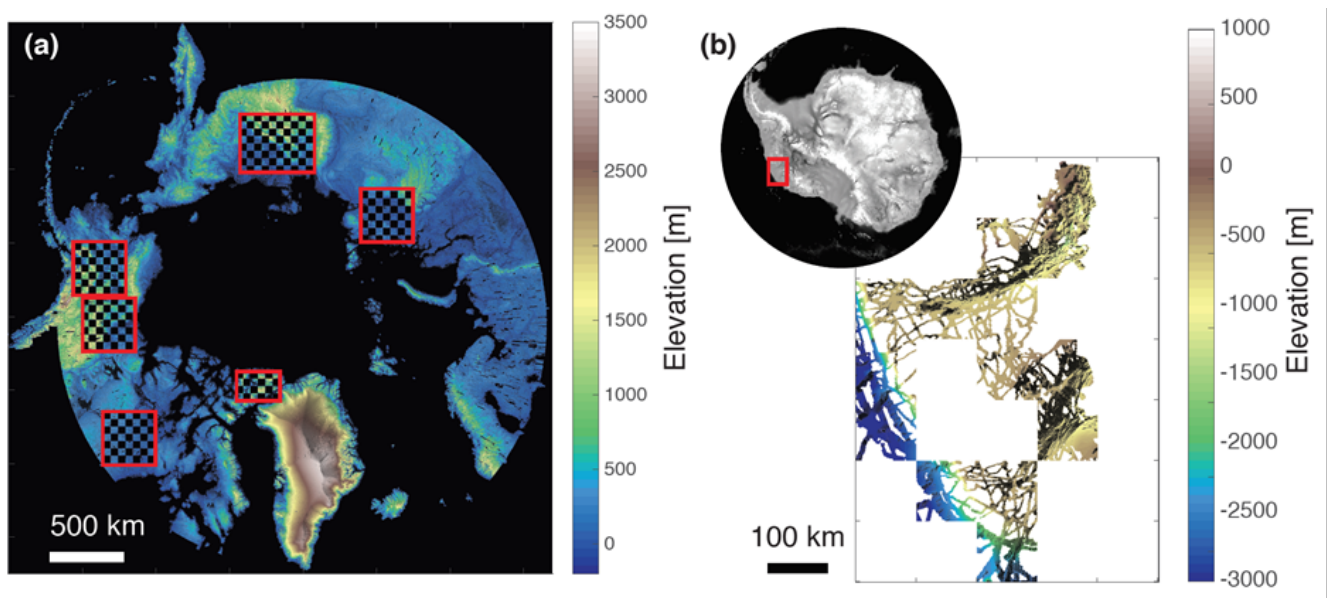

(c)
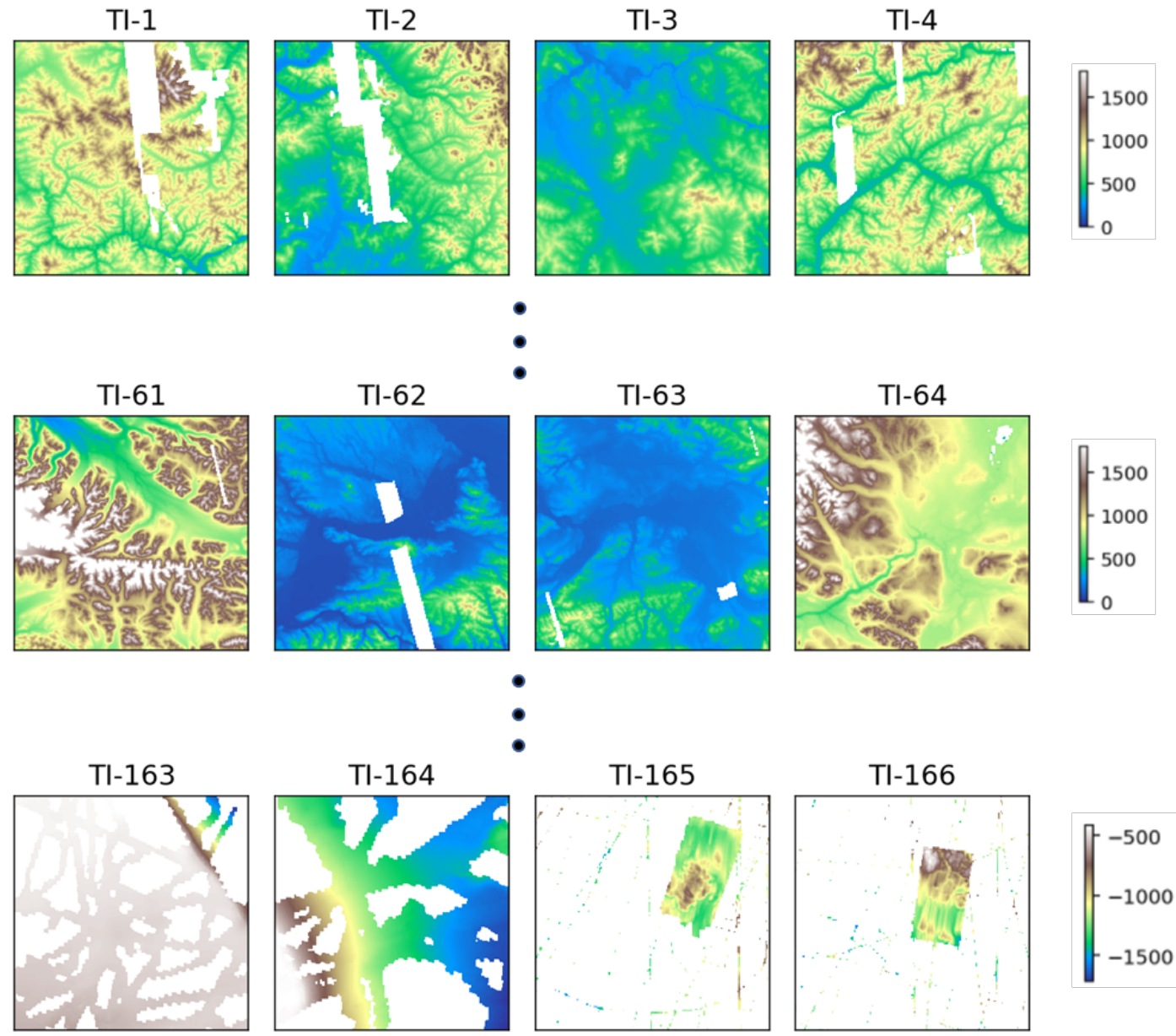

Figure 2. (a, b) Geographical locations of the 166 training images in (a): ArcticDEM and (b): Antarctica. (c) examples of the 166 training images 


\section{Methodology}

\section{$135 \quad 3.1$ Multiple-point geostatistics}

\subsubsection{Overview}

Multiple-point geostatistics (Journel and Zhang, 2006; Mariethoz and Caers, 2014; Srivastava, 2018; Strebelle, 2002) is the field of study that focuses on the digital representation of physical reality by reproducing high-order statistics inferred from training images. The emphasis in MPS lies on capturing higher-order (hence multi-point statistics) from training images that have been selected to be representative for a specific area of study. In that sense, it differs from spatial covariance-based (variograms) methods (e.g. Gaussian process regression or kriging) (Matheron, 1963; Williams and Rasmussen, 1996) that are based on spatial correlation (two values at a time). Both MPS and covariance-based methods have the ability to interpolate data exactly. Exact interpolation, if desired, is also where geostatistics differs from machine learning or computer vision methods, where such exact interpolation is not usually considered important.

Several MPS simulation algorithms (e.g. Gravey and Mariethoz, 2020; Hoffimann et al., 2017b; Mariethoz et al., 2010; Strebelle and Journel, 2001) have been developed that use training images to generate multiple realizations that interpolate the data exactly. The algorithm used in this work is Direct Sampling (DS) (Mariethoz et al., 2010b; Mariethoz and Renard, 2010), which will be introduced in section 0 . These algorithms do not address the challenge of selecting the training images themselves. For example, if an area of the simulation grid contains dense data, few training images may be compatible with that data. On the other hand, an area with sparse data may have many compatible training images. Finally, training images selected for two adjacent areas are not necessarily independent from each other.

To date, there has not been any attempt to use MPS to interpolate ice-penetrating radar measurements of topography at the 155 scale of the Amundsen Sea Embayment. In doing so, additional challenges occur that are not present in smaller study areas. The challenges may include limited amount of training images, non-stationarity over the ASE, and running time cost when generating high-resolution topographic maps. Before moving to the methodology that addresses these challenges, we first introduce the Direct Sampling method and a probabilistic framework for representing training images in metric spaces.

\subsubsection{Direct Sampling (DS)}

160 Direct sampling is a widely used MPS approach for achieving spatial modeling and gap filling (Mariethoz, 2018; Mariethoz et al., 2012; Zuo et al., 2020). Figure 3 provides a simplified example of DS in the context of flight lines. The values in the grid indicate the elevation. In general, there are two major components within DS. First, the algorithm visits an unknown location in the simulation grid and collects neighboring observed points as conditioning data. For example, in Figure 3(a), three conditioning points are detected near a unknow location (marked with “?”). DS records the values and relative locations

165 of known points. Second, a searching program is launched to find the similar structure in TI. The similarity within DS is 
defined by a certain distance metric. As Figure 3(d) shows, the program finds a matching structure. The center of the similar instance is pasted into the simulation grid. Thus, the value of an unknown point is predicted. The preceding simulation program is repeatedly performed until there is no unknown point in the grid.

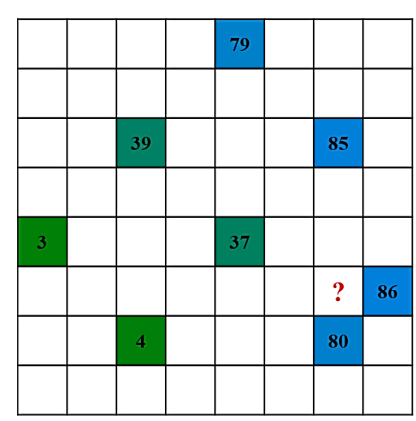

(a)

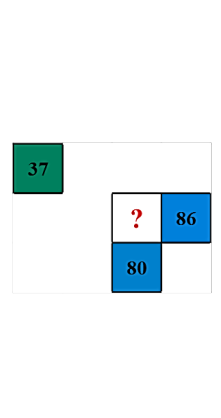

(b)

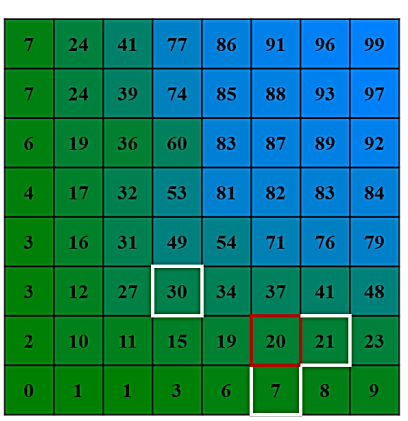

(c)
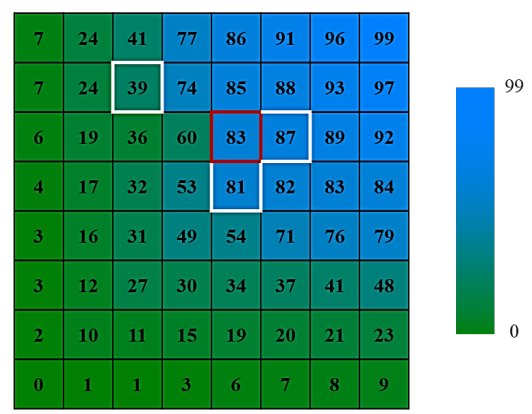

(d)

Figure 3. Conceptual example of the DS point simulation. (a) Radar lines on the simulation grid; (b) Three known points (value: 37 , 80, 86) constitute a conditioning data pattern; (c) A mismatch pattern in TI; (d) A similar pattern in TI.

Based on the explanation above, there are mainly three important parameters in DS. The first one is $n$, the number of

neighboring conditioning data points. It plays a key role in extracting complex patterns from the training images. In general, $n \geq 30$ is suggested to deal with a continuous simulation case (Bruna et al., 2019; Meerschman et al., 2013). Another parameter is the distance threshold $t$. It determines whether to accept a TI pattern based on the mismatch distance to the conditioning points. The TI pattern with mismatch distance below $t$ will be accepted and pasted to the simulation grid. $t$ therefore significantly affects the simulation efficiency and quality. A small value of $t$ could improve modeling quality but will result high computational burden. $t=0.1$ is generally recognized as the upper bound in the most cases (Meerschman et al., 2013; Zuo et al, 2020). The third main DS parameter $f$ is the fraction of scanned TI. With the intention of saving time and avoid verbatim copy, an recommended value of $f$ is between 0.1 and 0.5 (Mariethoz and Caers, 2014).

\subsubsection{A metric space for training images}

A metric space expresses the relationship between objects by using a distance function defining the similarity between any two objects. In metric spaces, we do not know the exact coordinates of objects, only how far objects are apart. Metric spaces are therefore useful in representing high-dimensional objects, such as training images. In this paper, we employ metric spaces for two purposes: 1) to visualize the difference between training images and 2) to estimate probabilities of training images to occur over some area.

190 To define a meaningful distance between any two training images, we create a set of representative patterns for each training image. The TI morphological features are mainly concerned when creating representative patterns to compute the distance. 
This requires first removing the effects of the original TI elevations. To do so, we rescale each TI to range between 0 and 1 by min-max normalization (Han et al., 2012). Then, like other MPS approaches such as SNESIM (Strebelle, 2002) and DISPAT (Honarkhah and Caers, 2010), we extract the spatial patterns from each TI with a fixed template. We then use the classical agglomerative hierarchical clustering (Romary et al., 2015) to divide the spatial patterns of each TI into a finite number of groups. The group number in agglomerative hierarchical clustering is determined by a distance threshold (between the clustered groups). We referred to the commonly used distance threshold in DS approach to set it as 0.1 (Meerschman et al., 2013) of the maximum pattern distances of the TI. The TI with more complex spatial patterns will therefore have more clustered groups. The medoid pattern of each group is taken as the representative pattern of that group. Figure 4 shows a few representative patterns. The distance used in the clustering is the normalized Euclidean distance.

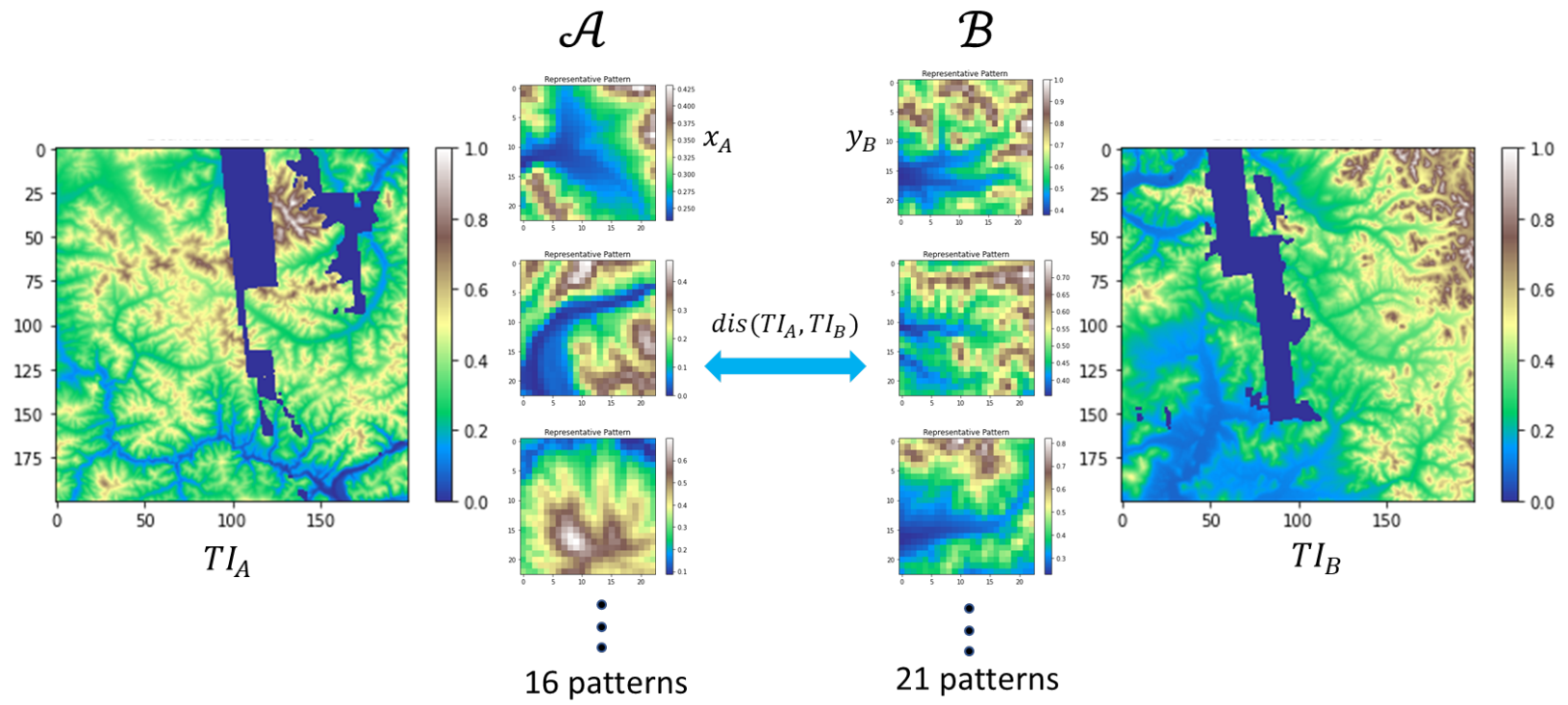

Figure 4. Calculating the distance between any two training images using modified Hausdorff distance.

After clustering and medoid selection, training images are now represented expressed by a set of representative patterns. We define the difference between any two training images as the difference between their sets of representative patterns. To do this, we use the modified Hausdorff distance (Dubuisson and Jain, 1994; Huttenlocher et al., 1993). This distance is commonly used to define the difference between shapes of high-dimensional objects. If we call the set of representative patterns for training image $\mathrm{A}$ as $\mathcal{A}$ and for training image $\mathrm{B}$ as $\mathcal{B}$, then the modified Hausdorff distance is

$\operatorname{dis}\left(T I_{A}, T I_{B}\right)=\max \left\{\frac{1}{|\mathcal{A}|} \sum_{x_{A} \in \mathcal{A}} \min d\left(x_{A}, \mathcal{B}\right), \frac{1}{|\mathcal{B}|} \sum_{y_{B} \in \mathcal{B}} \min d\left(y_{B}, \mathcal{A}\right)\right\}$

where $x_{A}$ is any representative pattern in $\mathcal{A}$, and $y_{B}$ is any pattern in $\mathcal{B} . d($.$) is the Euclidean distance between any two$ representative patterns. $|\mathcal{A}|$ and $|\mathcal{B}|$ are respectively the sizes of $\mathcal{A}$ and $\mathcal{B}$. In essence, the modified Hausdorff distance 
represents the maximum of expected minimum distances between the two TIs' representative patterns. Once a distance is defined, we can visualize the metric space in low-dimensional Cartesian space using multi-dimensional scaling or MDS

215 (Scheidt et al., 2018). MDS projects high-dimensional objects into a 2D cartesian space, where the difference between points in that space approximates the Hausdorff distance. Figure 5 show the projection of 166 training images in 2D, each dot represents a training image. Training images that are similar map close to each other in the scatterplot.

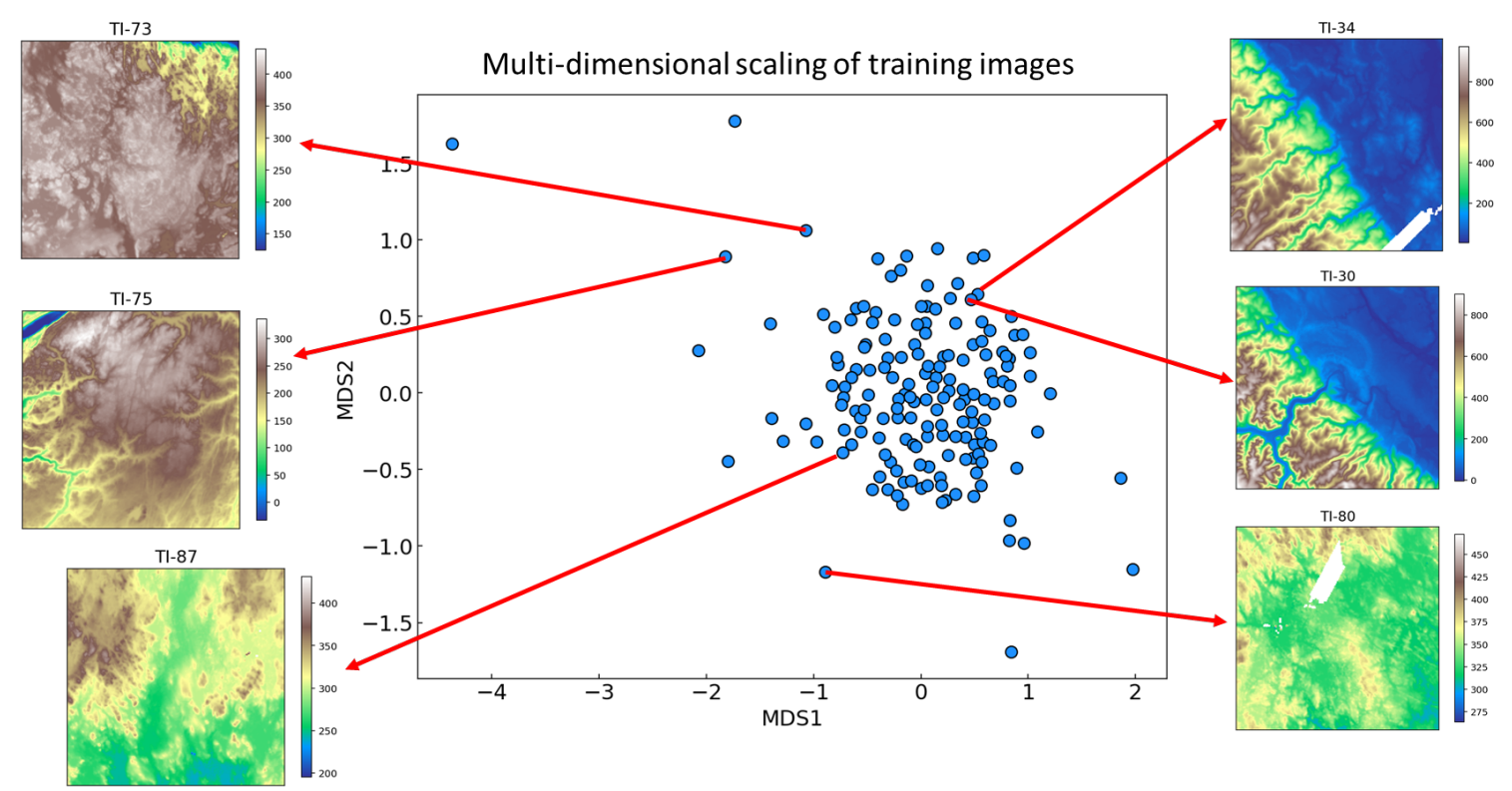

220 Figure 5. Visualization of the metric space using multi-dimensional scaling (MDS) into a two-dimensional cartesian space. Each dot on the plot represents a $\mathrm{TI}$.

\subsection{Illustration case \& overview of the mapping strategy}

To illustrate the proposed methodology, we focus on a small area of the ASE overlapping Pine Island Glacier (see Figure 6).

In this area, we observe a variety of radar line geometries and densities, as well as elevation changes. This smaller area is divided into 4 subareas. Strategies for such subdivision will be discussed later in the application to the entire domain.

Direct sampling, by construction, avoids any artifact boundary, because the data template is not aware of the subareas. With this strategy, two problems now need to be addressed. First, we need to find training images that are consistent with radar data within a selected area. There could be multiple such training images. Second, we need to model training image cross-correlation between different areas. Training images of two adjacent areas are not necessarily independent. Our approach is to model the posterior distribution of each area through a probability aggregation problem. 
https://doi.org/10.5194/gmd-2021-297

Preprint. Discussion started: 14 September 2021

(c) Author(s) 2021. CC BY 4.0 License.

(c) (i)
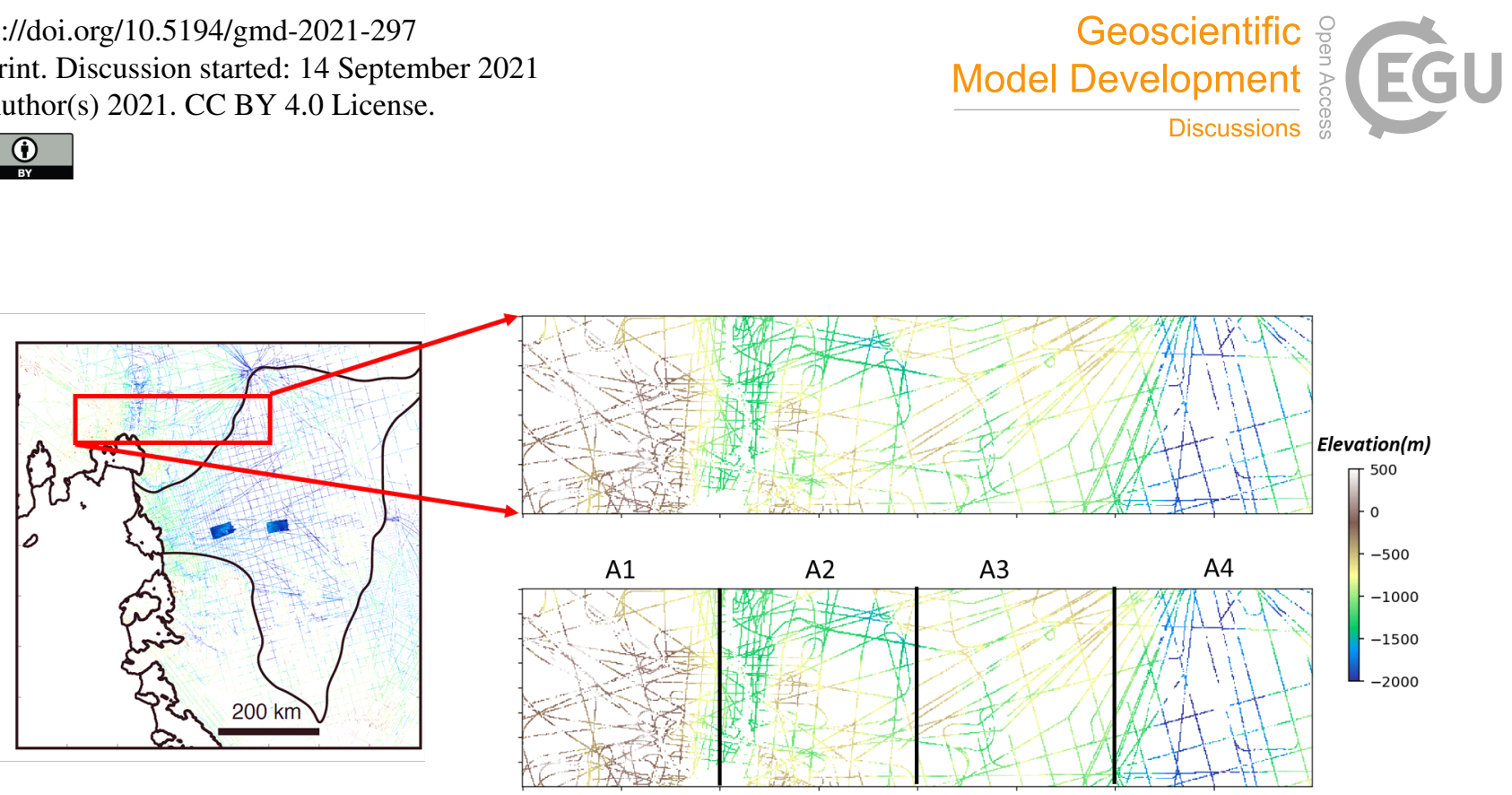

Figure 6 a subset of the pine island glacier is used to illustrate the methodology.

\section{$235 \quad 3.3$ Formulation of the problem through probability aggregation}

Our goal is to estimate, for each area $A_{1}, \ldots A_{4}$ the posterior distribution of the training image, given the flight radar line data $d_{A_{i}}$, or

$P\left(T I\left(A_{i}\right) \mid d_{A_{1}}, d_{A_{2}}, d_{A_{3}}, d_{A_{4}}\right)$

$\operatorname{TI}\left(A_{i}\right)$ is a discrete random variable that has 166 possible outcomes. To achieve this, we first estimate individual conditional probability $P\left(\operatorname{TI}\left(A_{i}\right) \mid d_{A_{j}}\right)$, then aggregate them into a single estimate for Eq (2). We will use a simple aggregation model that uses log-ratios (Allard et al., 2012), as follows:

$245 \quad r_{i j}=\log \left(\frac{P\left(T I\left(A_{i}\right) \mid d_{A_{j}}\right)}{1-P\left(T I\left(A_{i}\right) \mid d_{A_{j}}\right)}\right)$

To aggregate these individual conditional probabilities, the log-ratios can be summed relative to the prior:

$r_{i}-r=\sum_{j=1}^{4}\left(r_{i j}-r\right)$

250 Here, $r_{i}$ is the log-ratio of $P\left(\operatorname{TI}\left(A_{i}\right) \mid d_{A_{1}}, d_{A_{2}}, d_{A_{3}}, d_{A_{4}}\right)$ in Eq (2). $r$ is the log-ratio of the prior. The prior is a uniform distribution over all training images. Thus $r$ is calculated as:

$r=\log \left(\frac{P\left(T I\left(A_{i}\right)\right)}{1-P\left(T I\left(A_{i}\right)\right.}\right)=\log \left(\frac{1 / 166}{1-1 / 166}\right)=-5.10$ 
Then, we can solve Eq (4) for $r_{i}$ and invert the log-ratio to get $P\left(T I\left(A_{i}\right) \mid d_{A_{1}}, d_{A_{2}}, d_{A_{3}}, d_{A_{4}}\right)$.

However, in summing, we make a conditional independence assumption (Allard et al., 2012). Indeed, summing logarithms is equivalent to making products of the actual probabilities, which entails a form of conditional independence. Assuming conditional independence, when that assumption is untrue in reality, often results in overconfidence and too small uncertainty. To mitigate this issue, we add an additional weight term:

Logically, we would like the weight to account for the correlation between data in different regions. For example, if data of region $A_{i}$ is highly correlated with data in region $A_{j}$, then they are likely redundant with respect to the training image selection. Hence, we will make the weight $w_{i j}$ function of the correlation structure between different subareas. In the next section we will detail the subtasks ahead: 1) modeling and estimating $P\left(\operatorname{TI}\left(A_{i}\right) \mid d_{A_{j}}\right)$ and 2) calculating the weights $w_{i j}$.

\subsection{Probability of training images given radar line data.}

\subsubsection{Most probable set of training images}

A direct estimate of $P\left(\operatorname{TI}\left(A_{i}\right) \mid d_{A_{i}}\right)$ is challenging because the $d_{A_{i}}$ are very high-dimensional. We turn this high-dimensional problem into a low-dimensional as follows. Using the data $d_{A_{i}}$ in area $A_{i}$, we find those training images that constitute a set of most probable training image, i.e. those images closest to the radar line data in that area. Term this set as $\widehat{T I}$. Then given this set, we replace the radar line data with the most probable set:

$P\left(T I\left(A_{i}\right) \mid d_{A_{i}}\right) \cong P\left(T I\left(A_{i}\right) \mid \widehat{T I}\right)$

275 To determine this set, we solve the following optimization problem:

$\underset{\widehat{T I}}{\operatorname{argmin}}\left\{\operatorname{dis}\left(\mathbb{I}_{T I}(\widehat{T I}), d_{A_{i}}\right)\right\}$

where $\boldsymbol{T I}=\left[T I^{(1)}, T I^{(2)}, \ldots, T I^{(166)}\right]$ is the total set of training images. $\mathbb{I}_{\boldsymbol{T I}}$ is an indicator function which returns $\widehat{T I}$, a subset of $\boldsymbol{T I}$ of size $n$. We will explain how to determine the size $n$ of $\widehat{T I}$ in the Appendix. The distance dis in Eq (8) measures the 280 distance between the radar line data and any given training image. To calculate dis, we rely on the same modified Hausdorff distance approach as section 3.1.3: 
$\operatorname{dis}(T I, d)=\frac{1}{|\mathcal{D}|} \sum_{y_{D} \in \mathcal{D}} \min d\left(y_{D}, \mathcal{A}\right)$

$\mathcal{D}$ is now the set of patterns $y_{d}$ extracted from the radar lines. By pattern, we mean the radar line data are scanned within a given template. We use flexible sized templates when scanning the radar lines over each subarea $A_{i}$. The template size is randomly chosen between the maximum radius up to 15 pixels to include 40 measurement points. (Mariethoz and Caers, 2014, p160). $\mathcal{A}$ is the set of TI representative patterns $x_{A}$, obtained in section 3.13. Figure 7 provides an illustration of this idea.
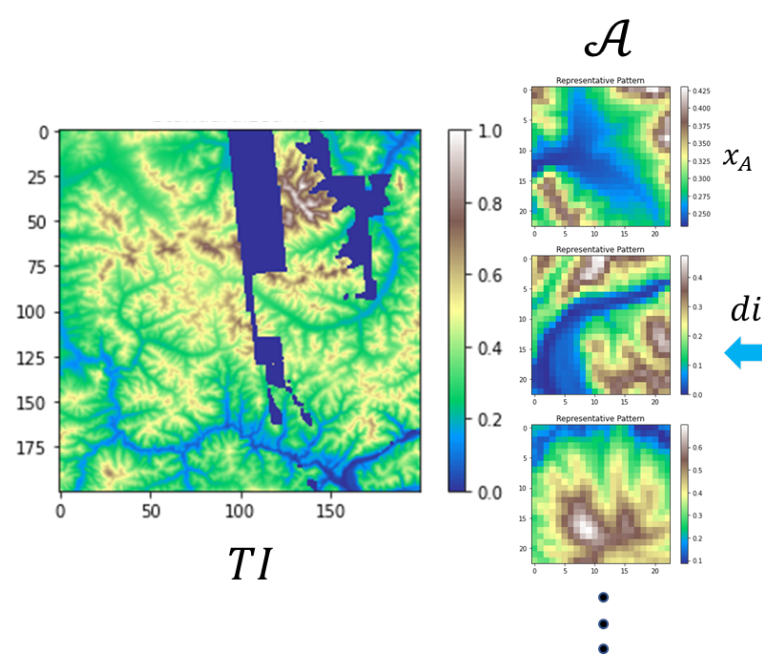

\section{$\mathcal{D}$}

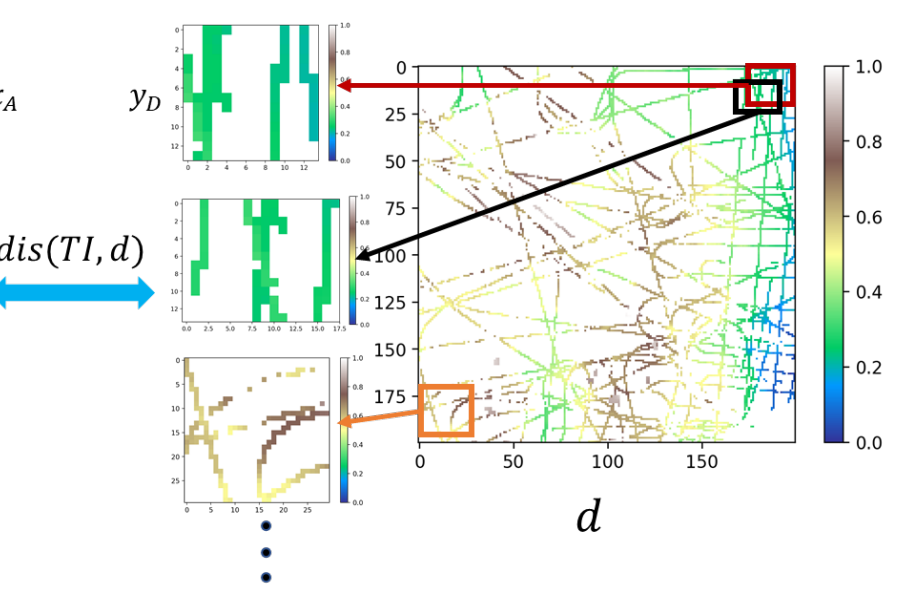

Figure 7. Illustration of measuring the distance between training image and radar line data.

We use a particle swarm optimization (PSO) to minimize the distance function $\operatorname{dis}\left(\mathbb{I}_{T I}(\widehat{T I}), d_{A_{i}}\right)$. As a heuristic optimization approach, PSO has its specific advantages in requiring less parameterizations, easy implementation, and fast convergency with good accuracy (Rezaee Jordehi and Jasni, 2013). These characteristics makes PSO a preferred optimizer for our initial training image selection. In conjunction with PSO, we employ the profile log-likelihood function to find the optimal size $n$ of $\widehat{T I}$. Detailed explanation on the PSO algorithm and profile log-likelihood function implementations is provided in the Appendix. Figure 8 shows the selected $\widehat{T I}$ in metric space for each subarea A1, A2, A3 and A4. In this figure, we also plot examples of $\widehat{T I}$ in the radar line map grid. 
(a)
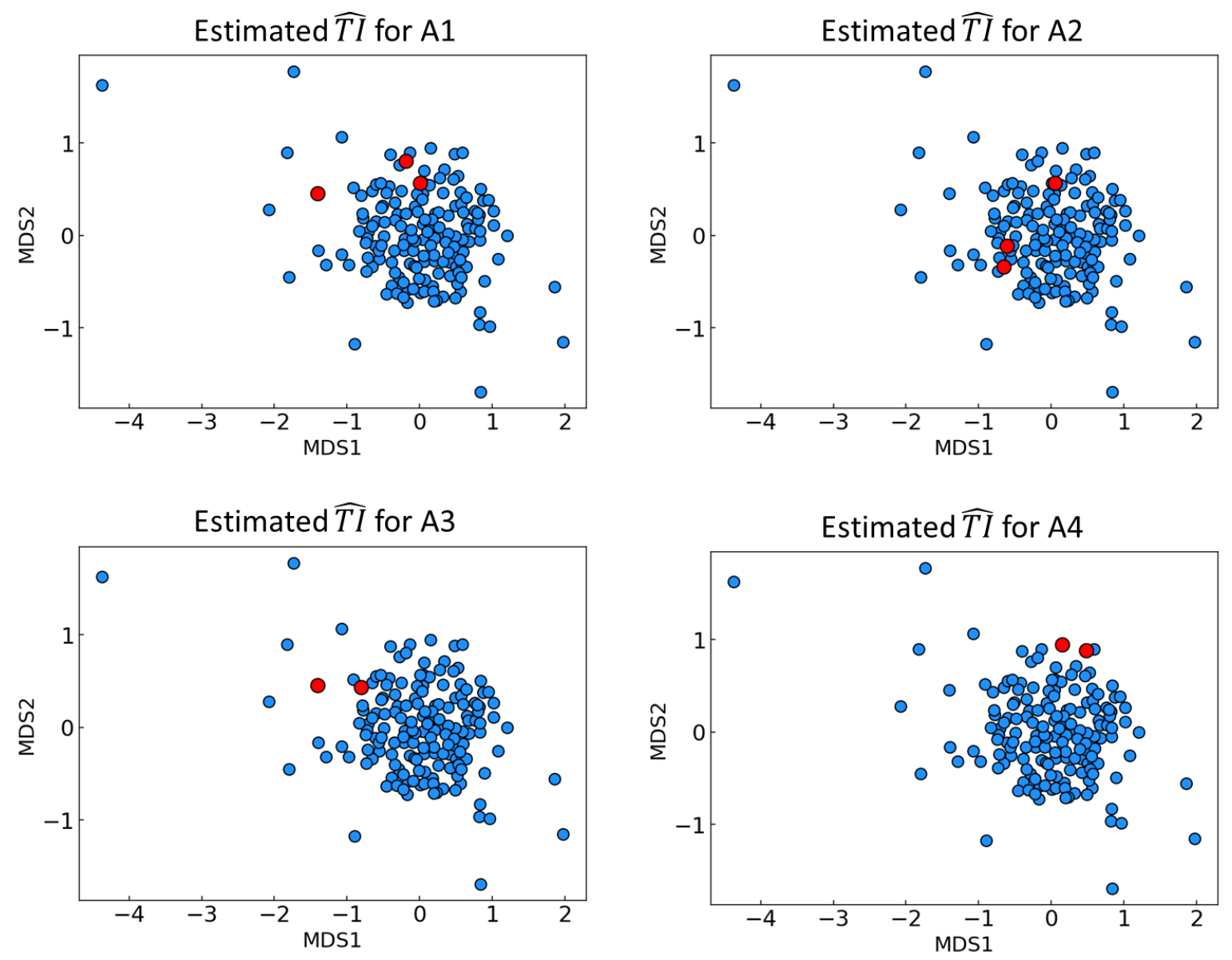

(b)

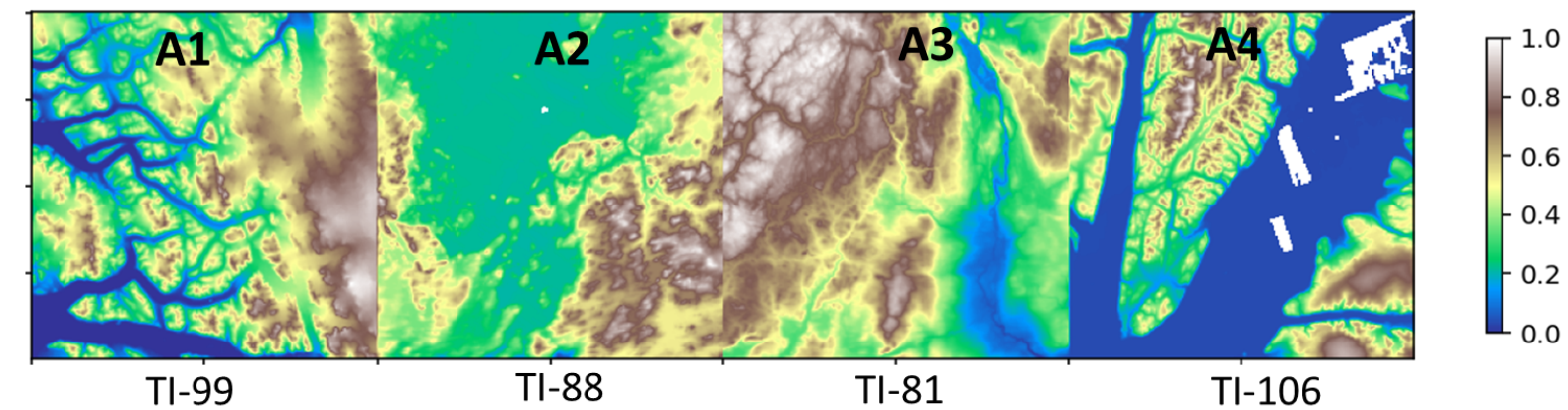

Figure 8. (a) The estimated set of most probable training images $\widehat{T I}$ for each area displayed on MDS plots. The red dots highlight the estimated $\widehat{T I}$. (b) Examples of $\widehat{T I}$ displayed in the topographic modeling space. 
https://doi.org/10.5194/gmd-2021-297

Preprint. Discussion started: 14 September 2021

(c) Author(s) 2021. CC BY 4.0 License.

(c) (i)

\subsubsection{Kernel density estimation of $P\left(\operatorname{TI}\left(A_{i}\right) \mid d_{A_{i}}\right)$}

We will use the optimal set of training images $\widehat{T I}$ to infer $P\left(T I\left(A_{i}\right) \mid d_{A_{i}}\right)$. We assume that the TIs near the $\widehat{T I}$ on MDS plot (Figure 4) tend to have similarly high probability of being assigned to the radar data subarea. This is because, from the TI 305 distributions in the MDS metric space, we can observe the spatial patterns of nearby TIs look similar. We therefore consider a Gaussian kernel density estimation (KDE) to predict the probability to each TI. The probability of each TI is estimated according to its distance with $\widehat{T I}$ in the MDS plot (Figure 5):

$P\left(T I\left(A_{i}\right) \mid d_{A_{i}}\right)=\frac{1}{n} \sum_{k=1}^{n} K\left(\frac{\operatorname{dis}\left(T I, \widehat{T I}_{k}\right)}{h}\right)$

310

$K(z)=\frac{1}{\sqrt{2 \pi}} \exp \left(-\frac{z^{2}}{2}\right)$

Here, $\widehat{T I}_{k}$ is the $k$-th selected TI using PSO. $n$ is the size of the set $\widehat{T I}$. $\operatorname{dis}\left(T I, \widehat{T I}_{k}\right)$ is distance between a $T I$ and $\widehat{T I}_{k} . K$ is the Gaussian kernel function (Eq (11)). The bandwidth $h$ is the variance of the Gaussian kernel. We choose the optimal bandwidth by Silverman's rule of thumb (Silverman, 1981). Figure 9 shows the KDE estimated probability of each TI for subarea A1.

(a)

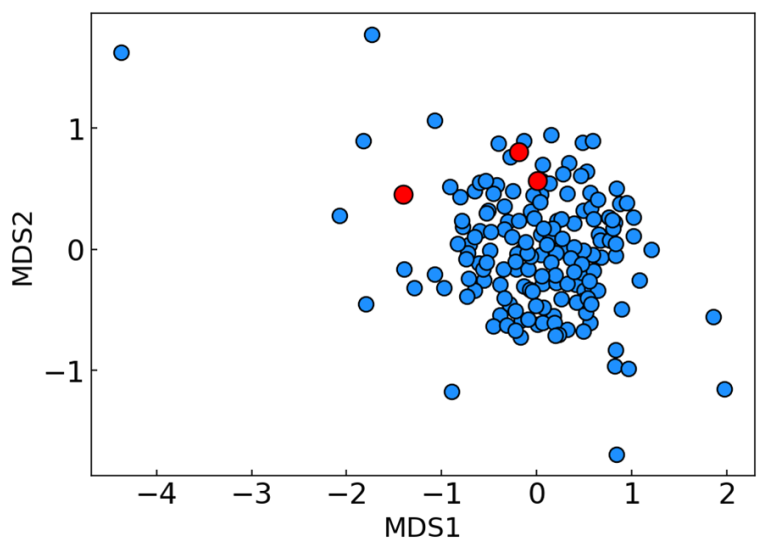

(b)

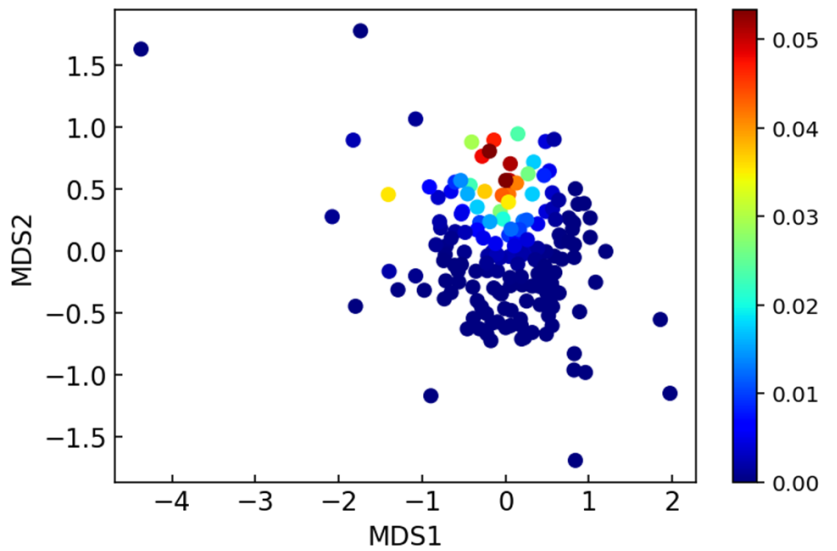

Figure 9. (a) Estimated $\widehat{T I}$ for A1. The TIs are plotted in MDS space. The red dots are $\widehat{T I}$. (b) Kernel density smoothing assigns likelihoods (densities) to the total set of training images by using $\widehat{T I}$.

\subsection{Aggregation by weighting log-ratios}

Next, we aggregate the $\mathrm{KDE}$ estimated probabilities by weighting the log-ratios to obtain the posterior

$P\left(T I\left(A_{i}\right) \mid d_{A_{1}}, d_{A_{2}}, d_{A_{3}}, d_{A_{4}}\right)$. The weights $w_{i j}$ required in the log-ratio aggregation of $\mathrm{Eq}(6)$ is to reflect the spatial correlation between the radar line subareas. We use a variogram-based approach proposed by Fouedjio (2020) to measure spatial 
https://doi.org/10.5194/gmd-2021-297

Preprint. Discussion started: 14 September 2021

(c) Author(s) 2021. CC BY 4.0 License.

(c) (i)

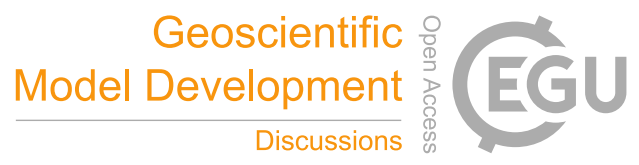

correlation between any two areas. In detail, the variogram dissimilarity is calculated as the sum of absolute values of all direct and cross variograms between the two areas.

$325 \operatorname{dissim}\left(A_{i}, A_{j}\right)=\frac{\sum_{l, l^{\prime}} K_{E}\left(\left(x_{i}, x_{j}\right),\left(x_{l}, x_{l^{\prime}}\right)\right) \times\left(z\left(x_{l}\right)-z\left(x_{l^{\prime}}\right)\right)^{2}}{2 \sum_{l, l^{\prime}} K_{E}\left(\left(\boldsymbol{x}_{i}, x_{j}\right),\left(x_{l}, x_{l^{\prime}}\right)\right)}$

where $\operatorname{dissim}\left(A_{i}, A_{j}\right)$ is the dissimilarity between area $A_{i}$ and $A_{j}$. According to Fouedjio (2020), $\left(\boldsymbol{x}_{i}, \boldsymbol{x}_{j}\right)$ are the spatial center locations of $A_{i}$ and $A_{j}$ respectively. $x_{l}$ and $x_{l^{\prime}}$ are the radar data locations in $A_{i}$ and $A_{j} . K_{E}(\cdot)$ is the Epanechnikov kernel function. $z(x)$ are the radar data measured values at location $x$. Using the calculated $\operatorname{dissim}\left(A_{i}, A_{j}\right)$, the weights $w_{i j}$ are 330 simply:

$$
w_{i j}=1-\frac{\operatorname{disim}\left(A_{i}, A_{j}\right)}{\max \left(\operatorname{disim}\left(A_{i}, A_{1}\right), \ldots, \operatorname{disim}\left(A_{i}, A_{j}\right), \ldots, \operatorname{disim}\left(A_{i}, A_{4}\right)\right)}, \text { where } i, j=[1,2,3,4]
$$

With $w_{i j}$, we can aggregate the probability using the Eq (4). Figure 10 shows the aggregated posterior probability of TIs for 335 each subarea. 

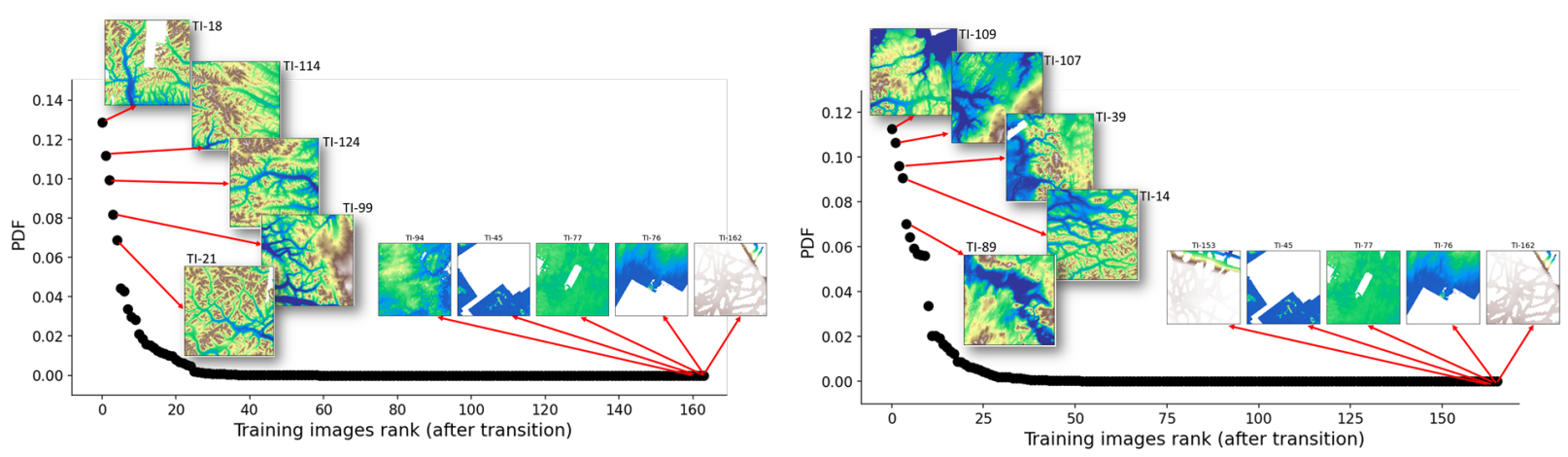

Final TI selecting probability for A3

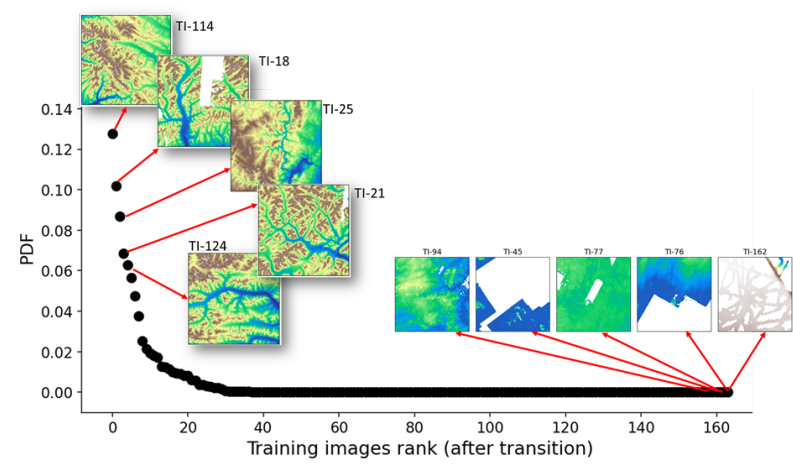

Final TI selecting probability for A4

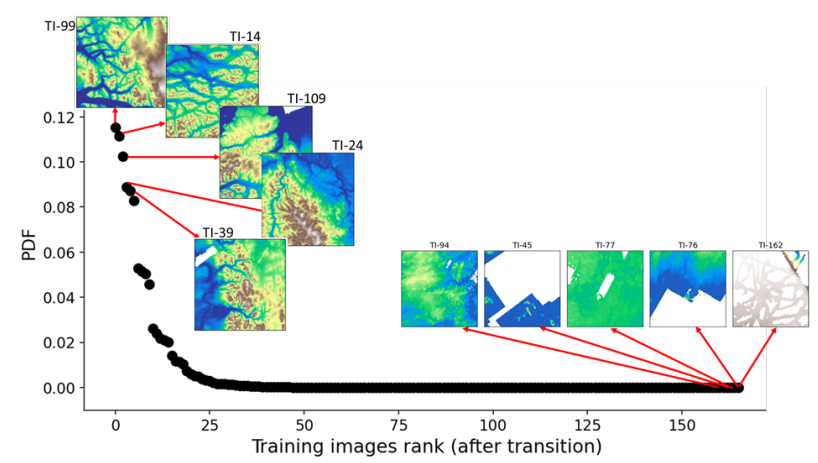

Figure 10. distribution of final aggregated TI probability in each radar line subarea.

\section{$340 \quad 3.6$ Direct sampling with TI sampling}

Using the aggregated posterior TI probability $P\left(T I\left(A_{i}\right) \mid d_{A_{1}}, d_{A_{2}}, d_{A_{3}}, d_{A_{4}}\right)$, we can now sample training images from the posterior distribution (Figure 10) in each subarea. Figure 11 plots two realizations of sampled training images on the radar line map. We observe that the sampled topography TIs are different between the realizations. For example, the TIs sampled for A1 tend to have higher elevations and more mountain peaks than A2. A2 and A4 tend to have larger scale low-elevation valleys that can be related to warm water routing, while the TIs in A1 and A3 data have more small-scale valleys. For each realization set of training images, we run a DS simulation. At the end, multiple realizations of topographical models are generated with multiple realizations of TIs. Figure 12 shows two example realizations of the DS simulated results. We can observe large valleys in A2 and A4 areas, while A1 and A3 areas mainly have high elevation peaks. The non-stationarity of both simulated topography realizations also agreed well with their sampled TIs, when compared to the TIs in Figure 11. 
https://doi.org/10.5194/gmd-2021-297

Preprint. Discussion started: 14 September 2021

(c) Author(s) 2021. CC BY 4.0 License.

(c) (i)

Realization \#1

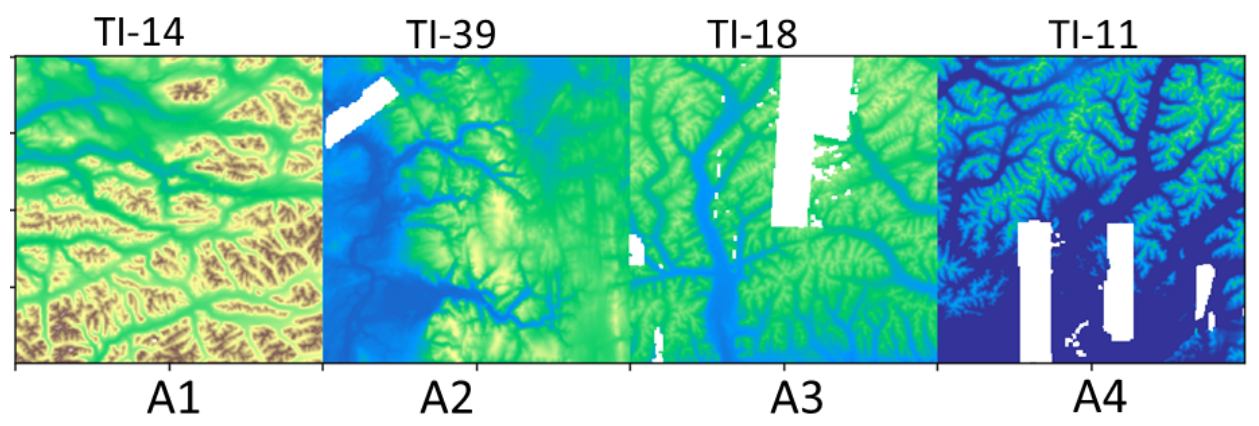

Realization \#2

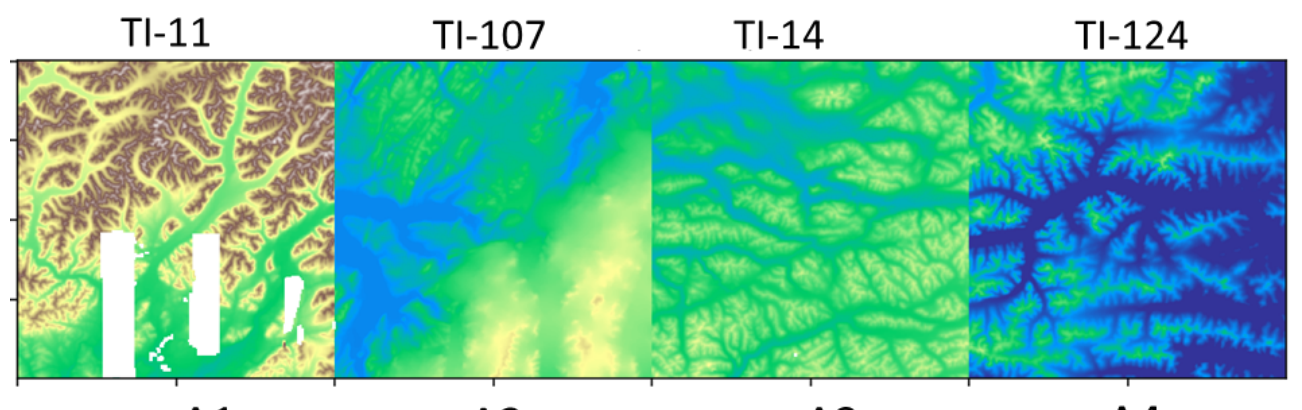

$\begin{array}{llll}\text { A1 } & \text { A2 } & \text { A3 } & \text { A4 }\end{array}$

Figure 11. Examples of sampled TIs from the posterior distributions. The TIs are rescaled back to the local radar data range by inverting the min-max normalization. 


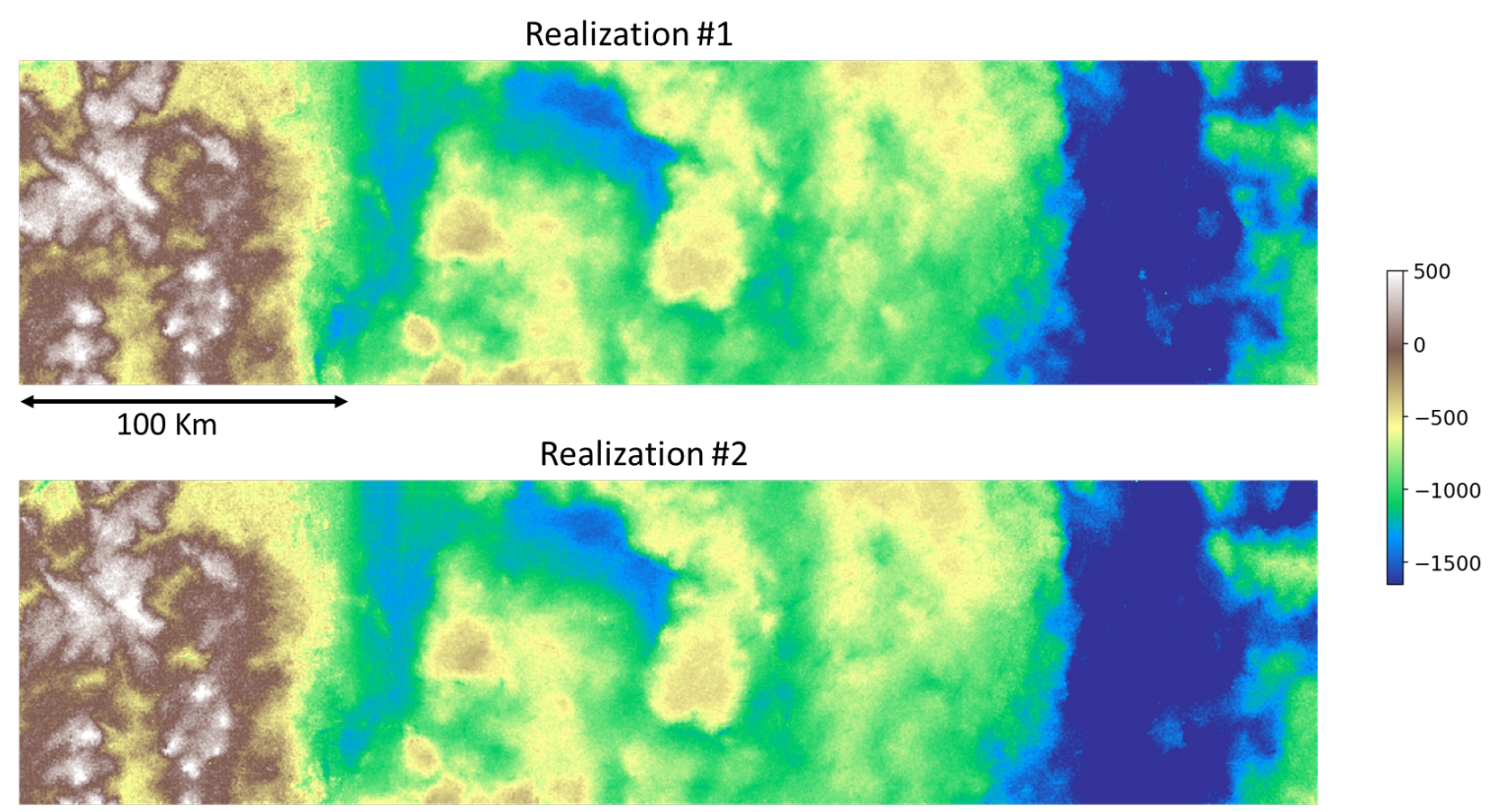

Figure 12. Two realizations of DS simulated topographical models by filling the radar line gaps. Model realization number corresponds to the TI realization number in Figure 11.

\subsection{Comparison with traditional MPS modeling and two-point geostatistical modeling}

Our results are compared to the conventional MPS simulation without proposed TI sampling. Here, we use the same DS

simulation parameters as our TI sampling approach, except that the training images are different. In the conventional test, we run the DS simulation by scanning all the 166 TIs to fill the radar line gaps. Figure 13a shows one realization of the simulated result. It is obvious that the conventional approach results in a much noisier topographical model. There are significant line artifacts that make the model unrealistic. To gain detailed understandings, we take a cross-section A-A' on the Pine Island glacier and plot the comparison in Figure 14. We can observe that the DS without TI sampling creates a significant amount unrealistic elevation peaks and troughs. Especially at the main channel of Pine Island glacial (marked by the dashed box in Figure 14) where mostly radar data are available, unrealistic channels are simulated between the radar data observations. This suggests that, when using all the 166 TIs without proper sampling, the DS finds too large a set of patterns likely many incompatible with the sparse data. Our TI sampling approach avoids this problem by limiting the algorithm to a small number of most suitable TIs, thereby improving the result. More importantly, avoiding the channel artifacts is critically important for modeling subglacial hydrological flow (see section 0). In terms of running time, the conventional DS approach with 166 TIs took nearly 21 hours to simulate one realization. When using our TI sampling approach, it took less than 1 hour. Our initial DS implementation tests are run on a PC with an Intel i9-11900 of 2.5GHz processor and 32GB of RAM. 
We further compare to the two-point geostatistical modeling with kriging and Sequential Gaussian Simulation (SGSIM).

375 Figure $13 \mathrm{~b}$ and Figure 13c plot topographic modeling results from kriging and SGSIM. We can observe that kriging produces the most smoothed topographical model. The over-smoothed features are very clear from the detailed cross-section in Figure 14. After all, kriging is a deterministic modeling approach. Thus, it cannot capture location scale elevation variations and quantify the spatial uncertainty. Our SGSIM approach uses local ordinary kriging; this way non-stationarity is addressed by limited the neighborhood of spatial inference. The limitation of SGSIM, an approach based on spatial covariances, lies on its 380 limitations in capturing complex morphological features, especially when the radar line data are very sparse (see the circle highlighted on Figure 13c). In Figure 15, we also compare the empirical variograms from the modeled topographical maps using the four different approaches. It shows the DS using sampled TIs has reproduced the observed radar data variogram. SGSIM maps also reproduce the variograms from the observed radar data, because it directly uses the radar data variograms for modeling. However, the DS without TI sampling has a nugget (noise) effect. Overall, it shows the TI sampling approach 385 performs the best in terms of improving the modeling speed, simulation quality, and capturing the spatial uncertainty. 

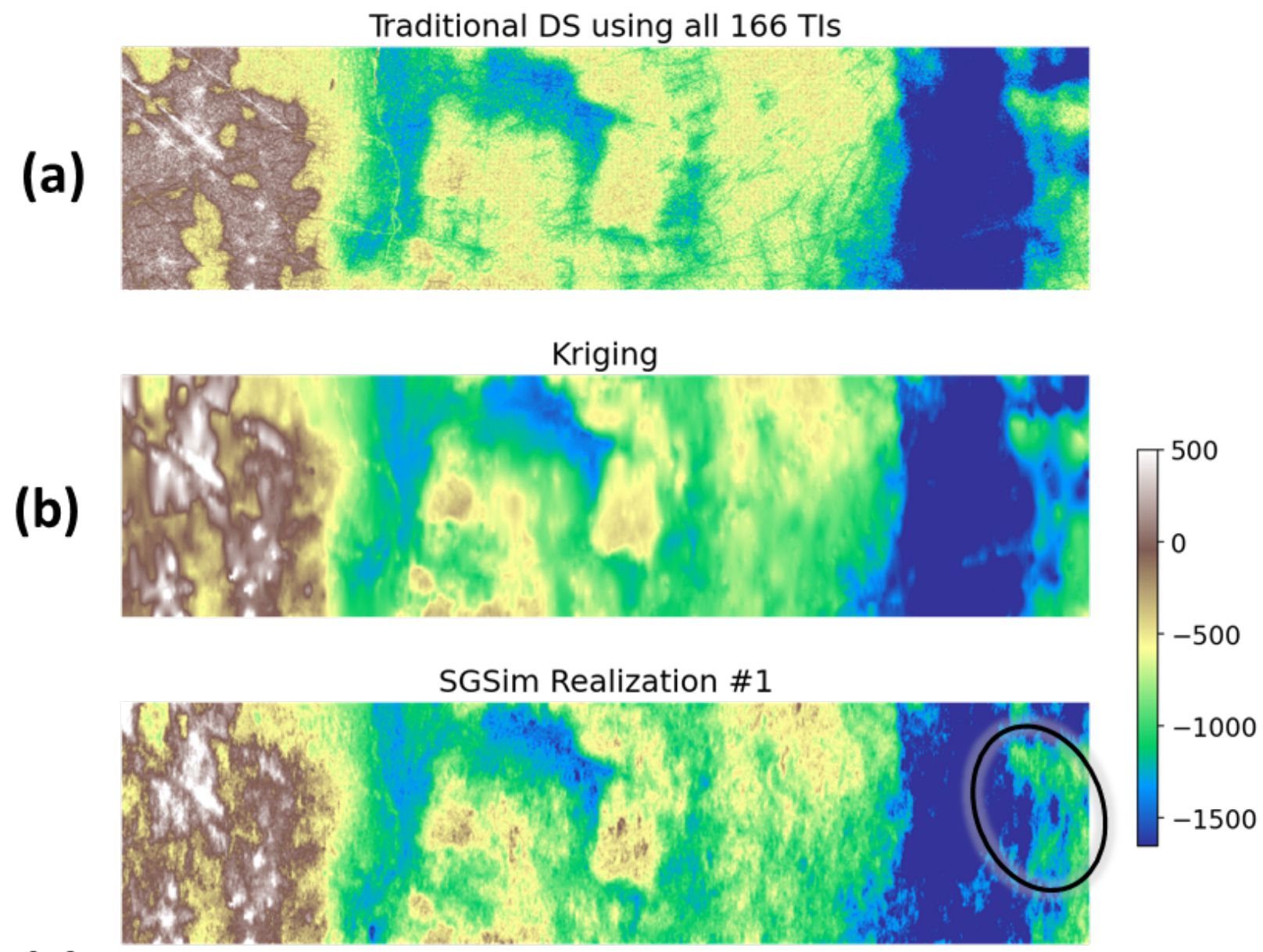

(c)

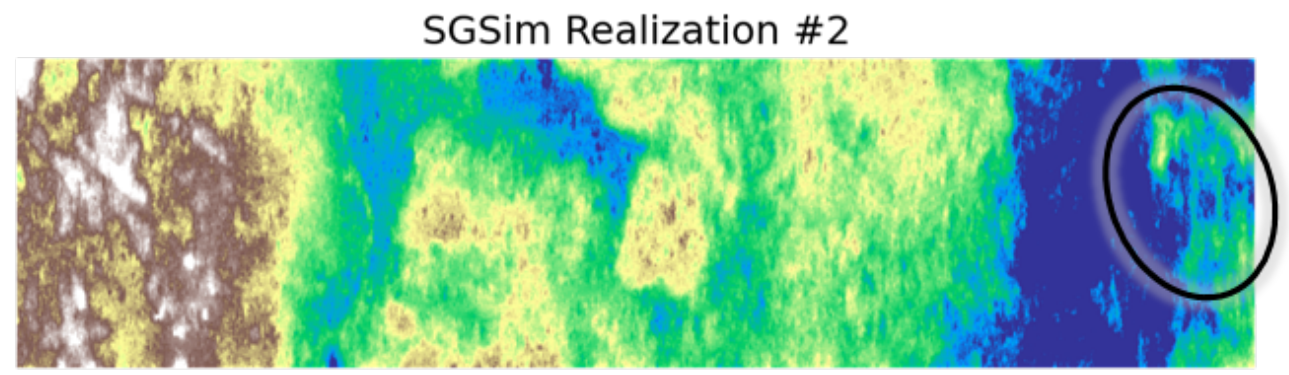

Figure 13. Subglacial topography modeled by - (a) traditional DS using all the 166 TS (without TI sampling), (b) kriging, (c) SGSIM. 
https://doi.org/10.5194/gmd-2021-297

Preprint. Discussion started: 14 September 2021

(c) Author(s) 2021. CC BY 4.0 License.

(c) (i)
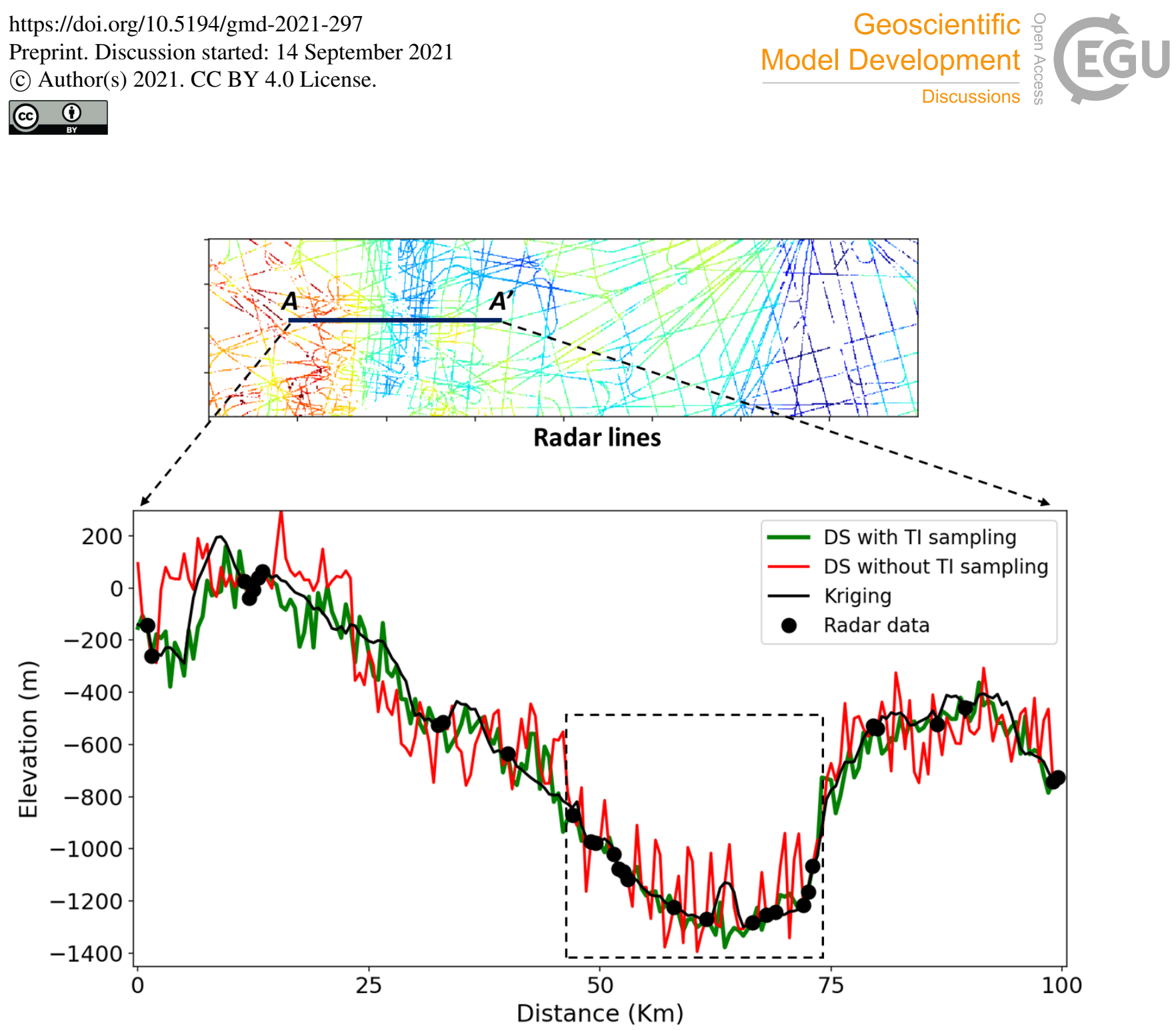

Figure 14. Cross-section view of the modeled topography maps at line A-A'.
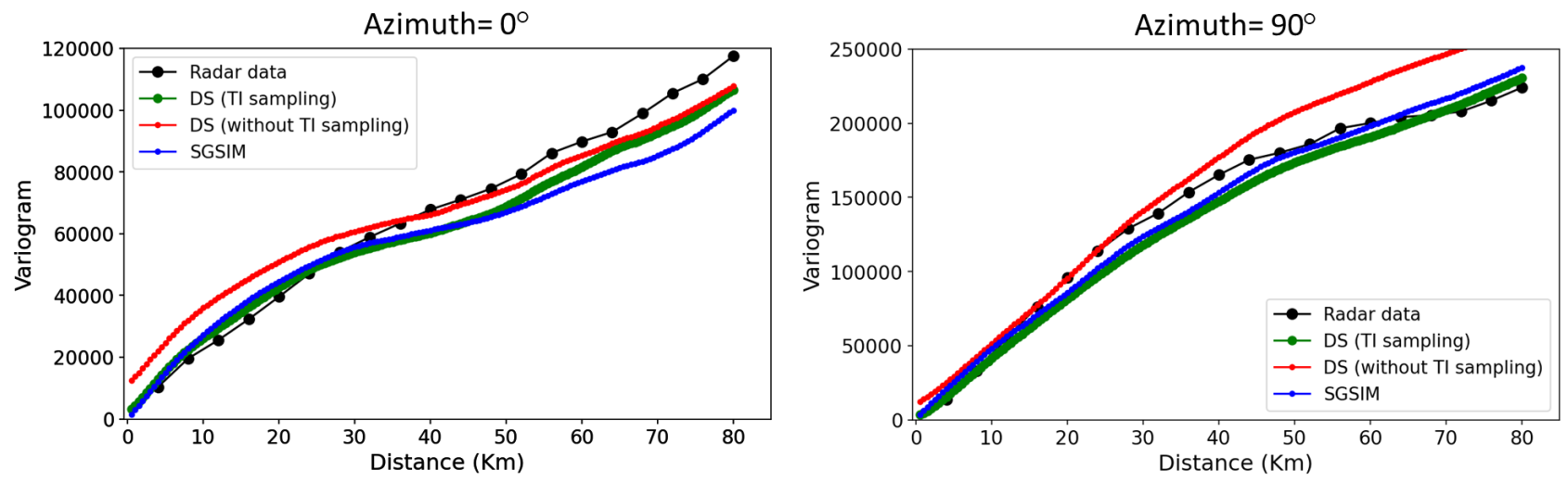

Figure 15. Variograms of the radar line data and modeled topography maps. 


\section{Application to the entire Amundsen Sea Embayment (ASE)}

\subsection{Training image sampling and DS simulation}

395 We apply the methodology to fill the radar lines gaps of the entire ASE area to generate high-resolution topography maps. To address the spatial non-stationarity and sample TIs, we first divide the whole ASE area into local subareas. We use the following recursive diving steps to divide the entire ASE into $L$ subareas based on the radar line data density:

Step 1. Equally divide the ASE area into four subareas.

Step 2. For each subarea, if it has more than $N$ radar data points, continue to divide it into four equally size areas.

Step 3. Repeat step 2 until amount of data measurements is below the threshold amount $N$. In this case, we set $N=10000$ and divide ASE into totally of 56 subareas.

Figure 16 shows the final ASE subareas with the corresponding radar data density. Next, we calculate posterior TI probability for each subarea $P\left(\operatorname{TI}\left(A_{i}\right) \mid d_{A_{1}}, \ldots, d_{A_{L}}\right)$. We can then use the posterior probability to sample one single TI for each subarea. 405 Figure 17 plots two realizations of the sampled TIs in the entire ASE space. For each TI realization, we run DS to fill the radar line gaps to generate high-resolution topography maps. To reflect the spatial uncertainty, 20 topography map realizations are simulated using 20 realizations of TI sets. The generated high-resolution bed topography is shown in Figure 18.

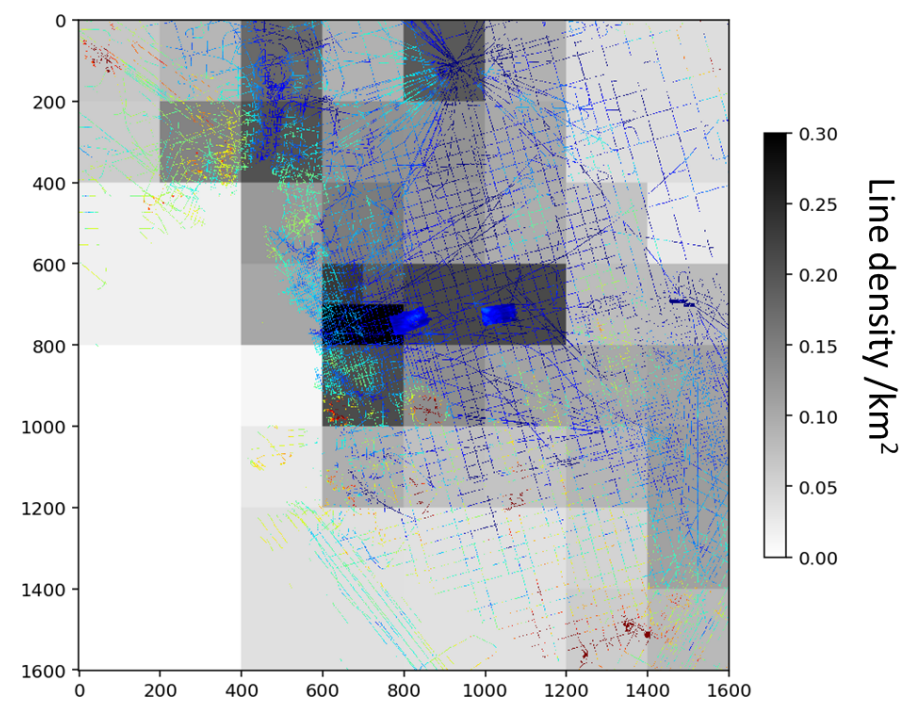

410 Figure 16. Subareas with corresponding data density, overlapped by the radar line data. 
https://doi.org/10.5194/gmd-2021-297

Preprint. Discussion started: 14 September 2021

(c) Author(s) 2021. CC BY 4.0 License.
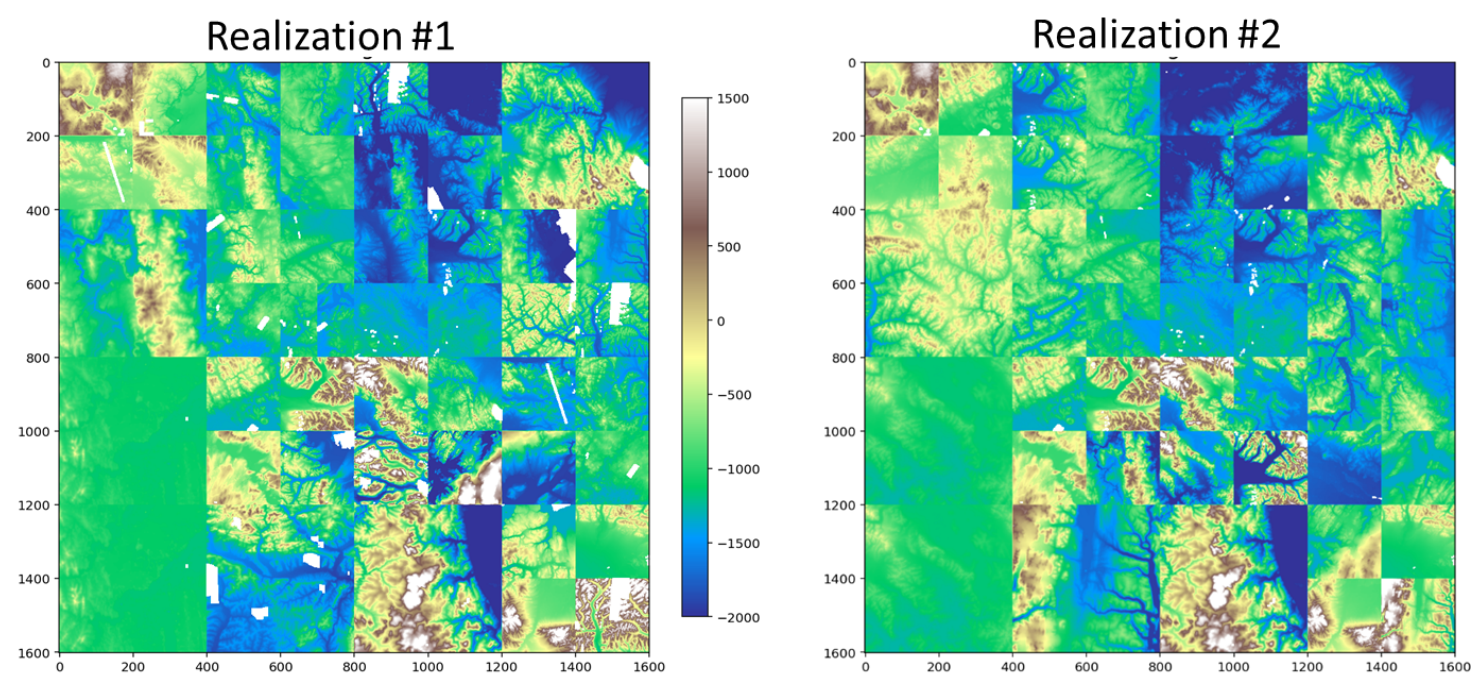

Figure 17. Two realizations of TIs assigned to the entire ASE area. 
https://doi.org/10.5194/gmd-2021-297

Preprint. Discussion started: 14 September 2021

(c) Author(s) 2021. CC BY 4.0 License.

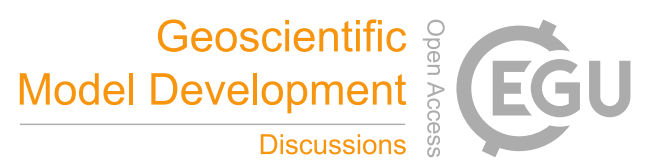

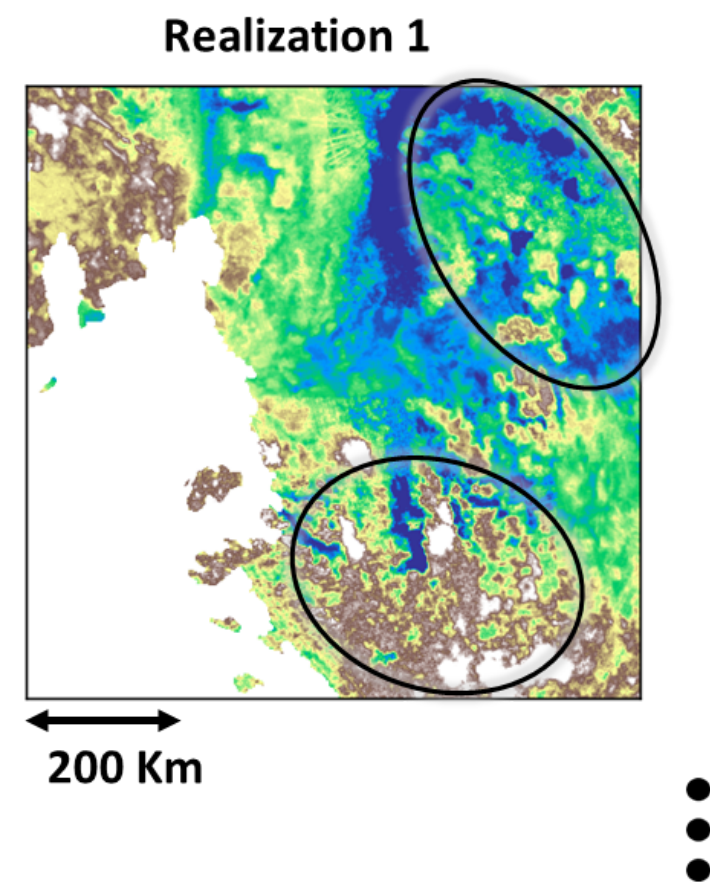

Realization 19

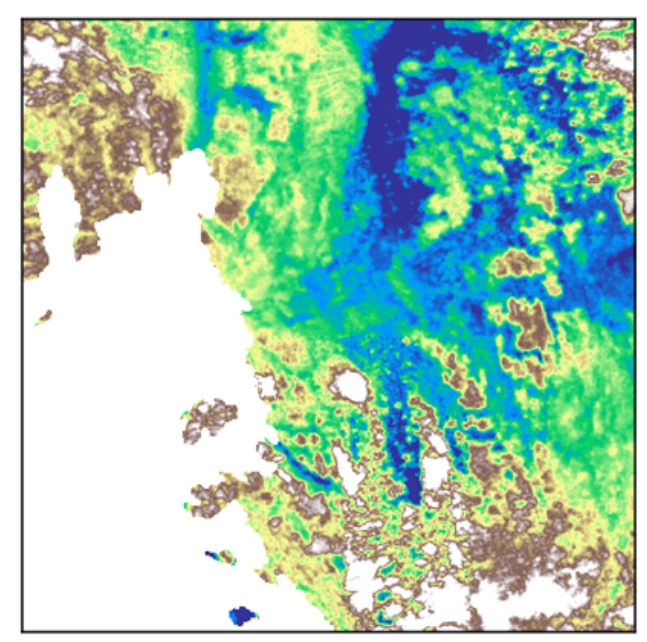

\section{Realization 2}

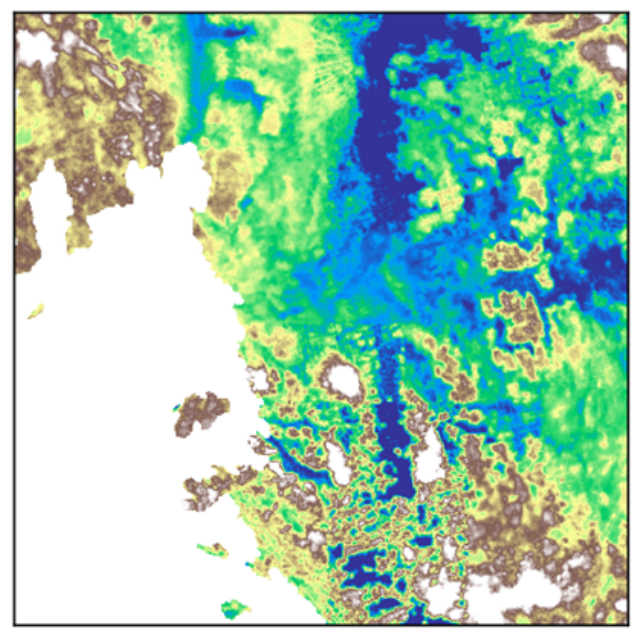

0

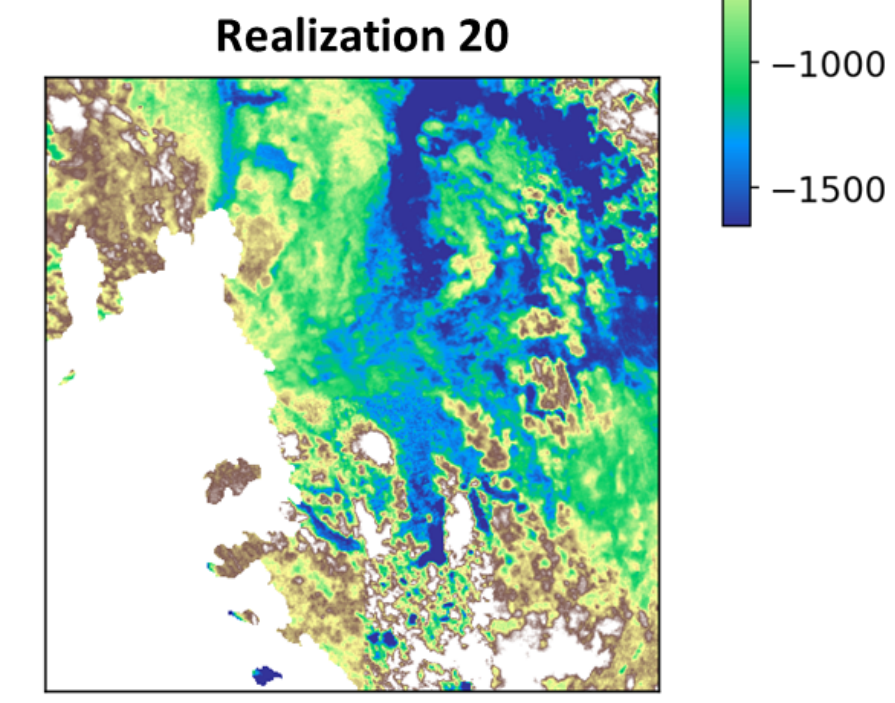

415 Figure 18. Realizations of the ASE topography after filling the radar line gaps. The circles highlight the areas with high spatial variations across the realizations. 
https://doi.org/10.5194/gmd-2021-297

Preprint. Discussion started: 14 September 2021

(c) Author(s) 2021. CC BY 4.0 License.

(c) (i)

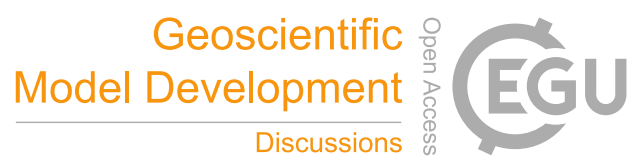

\subsection{Uncertainty in subglacial hydrological flow.}

We use the topographic realizations to investigate the sensitivity of subglacial water routing to topographic uncertainty. A water routing model was applied to 20 realizations to model the flow of water at the ice/bed interface. The direction of water flow is determined by calculating hydraulic potential, $\phi$, using the Shreve equation (Shreve, 1972):

$\phi=\rho_{w} g h+\rho_{i} g H$,

where $\rho_{w}$ is the density of water $\left(100 \mathrm{~kg} \mathrm{~m}^{-3}\right), \rho_{i}$ is the density of ice $\left(917 \mathrm{~kg} \mathrm{~m}^{-3}\right), g$ is gravitational acceleration, $h$ is bed elevation, and $H$ is ice thickness. The hydrological model is implemented using the Antarctic Mapping Tools (Greene et al., 2017) and the FLOWobj function and multiple flow directions (MFD) algorithm from the TopoToolbox package (Schwanghart and Scherler, 2014).These functions use the hydraulic potential gradient to compute flow accumulation, or the number of pixels that flow into another pixel. We assume spatially uniform basal melt rates and that the water pressure is equal to the ice overburden pressure.

The water routing models vary across each realization (Figure 19). In particular, the Thwaites Glacier tributaries flowing towards the grounding line (area where the ice meets the ocean and decouples from the bed) show significant differences across each realization. These tributaries are located near a system of active subglacial lakes - lakes at the ice/bed interface that periodically drain and refill (Smith et al., 2017). These lakes are hypothesized to be hydrologically connected, with a drainage and refill cycle that depends on the level of connectivity (Smith et al., 2017). Lake drainage events are associated with increases in ice velocity (Stearns et al., 2008), making it important to characterize the connectivity of active lake systems. Our results could be used to investigate the nature of hydrological drainage at Thwaites and highlight areas that require additional observational constraints. 
https://doi.org/10.5194/gmd-2021-297

Preprint. Discussion started: 14 September 2021

(c) Author(s) 2021. CC BY 4.0 License.

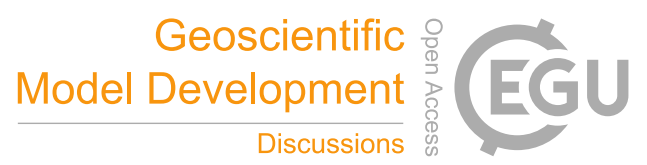

(a)

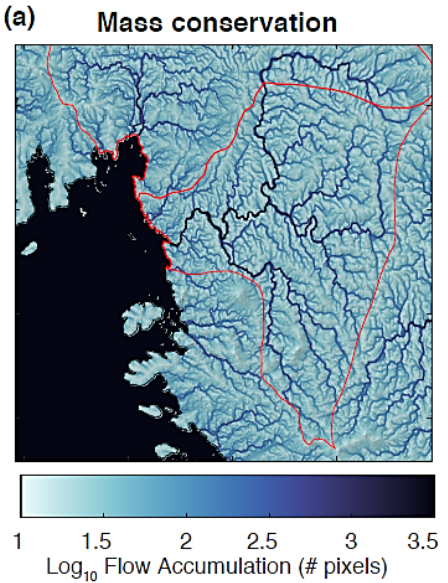

(d)

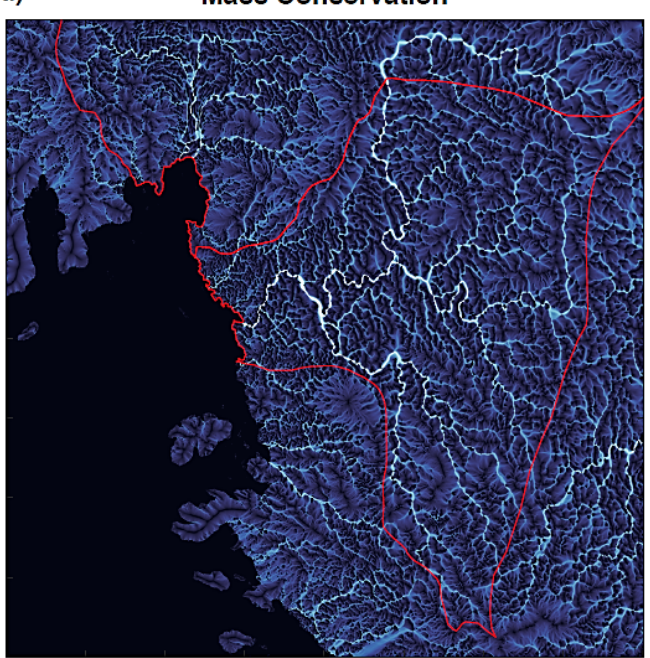

Flow Accumulation for

(b)

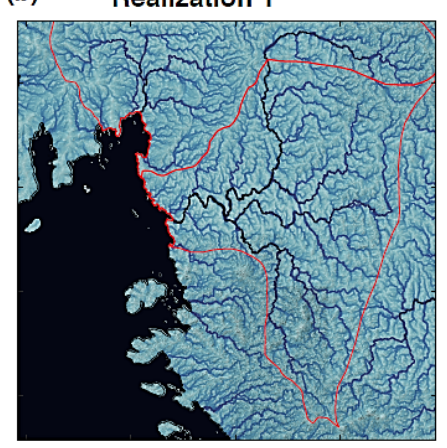

— Glacier boundaries (c) Realization 2

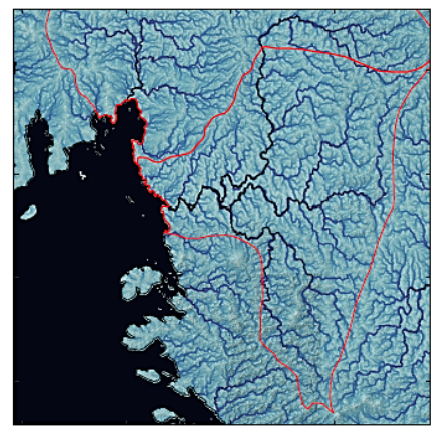

(e)

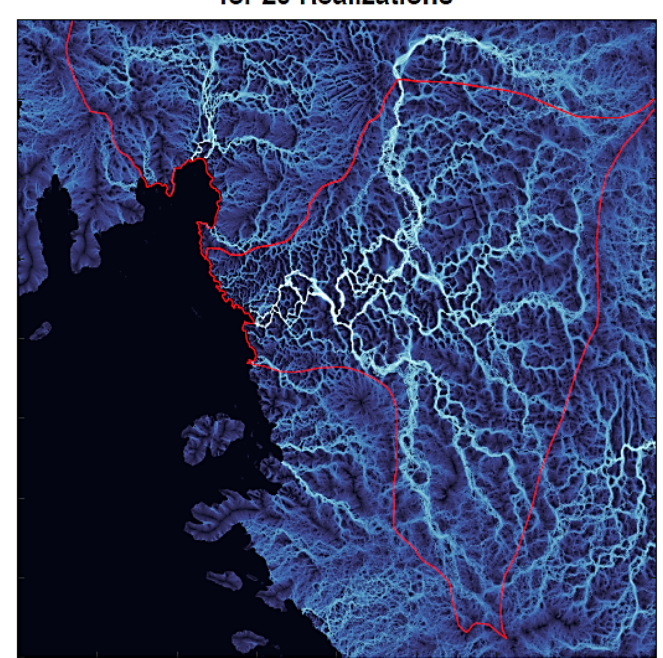

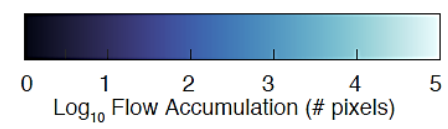

Figure 19. (a) subglaical water routing from mass conservation; (b) and (c) water routing using two topographic realizations from our DS simulation with TI sampling; (d) flow accumulation for mass conservation; (e) mean flow accumulation for 20 topographic realizations from our DS simulation.

\section{Conclusions}

We developed a non-stationary multiple-point geostatistical approach to fill large-scale geophysical data gaps and applied it to map high-resolution subglacial topography in West Antarctica. The radar data gaps were filled using morphological features 
learned from high-resolution topographic training images. To reflect the geospatial uncertainty, we modeled multiple realizations of topography maps using 166 high-resolution training images from the Arctic and Antarctica. These training images represent the diversity of subglacial geologic settings. We have placed them in a publicly accessible repository for training subglacial topography models. The TI repository can be further expanded in the future upon the acquisition of additional swath bathymetry and swath radar measurements.

Our major contribution was to show a probabilistic method to model posterior TI probabilities, then sample TIs to model the global non-stationarity in subglacial topography. This was achieved by probabilistically assigning non-stationary TIs from the provided repository to the local radar data. We used the collected 166 topographic training images as prior. The posterior distribution is calculated based on the distance between each TIs and local radar data. To address the spatial correlation across the global area, we aggregate the TI probability between the local areas based on their spatial correlation. The aggregated posterior TI distribution allowed us to sample training images. Finally, we ran direct sampling to fill the radar line gaps. Multiple realizations of high-resolution topography maps were generated using multiple realizations of sampled training images. Such non-stationary TI sampling framework avoided the use of auxiliary variables and arbitrary ad-hoc weighting. It significantly improved the topography modeling quality from DS. It also dramatically reduced the DS running time when giving large amount of training images. Compared to the traditional deterministic interpolation (kriging) and two-point geostatistical simulation (SGSIM) approaches, our approach was shown to provide more realistic topographic maps for spatial uncertainty quantification, whilst retaining the spatial correlation measured by radar data.

We applied our proposed approach to fill the radar line gaps for entire the Amundsen Sea Embayment in West Antarctica. The improved modeling efficiency enabled us to simulate 20 realistic high-resolution topographic maps on a local PC. We then used the 20 topographic realizations to investigate the sensitivity of subglacial water routing to topographic uncertainty. The results reveal significant variabilities in the Thwaites Glacier tributaries across realizations. These tributaries are near a system of active subglacial lakes, which are hypothesized to be hydrologically connected and could have the potential to influence ice sheet velocity. The high hydrological uncertainty in this area highlights the need for additional measurement constraints. These findings demonstrate the utility of geostatistically simulating subglacial topography rather than performing deterministic interpolations. Our non-stationary MPS framework provides a path forward for implementing geostatistical simulations at continental scales. 


\section{Appendix: Particle swarm optimization (PSO) and optimal TI numbers}

We perform particle swarm optimization to minimize the distance function $\operatorname{dis}\left(\mathbb{I}_{T I}(\widehat{T I}), d_{A_{i}}\right)$ in Eq (8). Following the PSO algorithm (Rezaee Jordehi and Jasni, 2013), we start with a random initialization of $m$ selected TIs). Each individual TI selection is regarded as an individual particle $\left(P_{i}\right)$. To find TIs that minimize the distance function, each particle will explore the whole TI space iteratively with a velocity $V_{i}$. The position (TI index) of $P_{i}$ at time step $t+1$ is determined by its previous position $P_{i}(t)$ and searching "velocity" $V_{i}(t+1)$.

The velocity $V_{i}(t+1)$ is determined by the particle's current logged best TI index $P_{i}^{\text {best }}$ and the best TI index $P_{g}^{\text {best }}$ for the whole swarm, as

$V_{i}(t+1)=w \times V_{i}(t)+c_{1} \times r_{1} \times\left(P_{i}-P_{i}(t)\right)+c_{2} \times r_{2} \times\left(P_{g}-P_{i}(t)\right)$

where $V_{i}(t)$ is the velocity from the previous time step. $w$ is the "inertia weight" that controls the contribution of $V_{i}(t)$ to $V_{i}(t+1)$. A smaller $w$ means less influence from the previous velocity, thus higher PSO exploration capability. Here we set $w$ as 0.8 according to the study by Han et al. (2010). $\mathrm{r} 1$ and $\mathrm{r} 2$ are two random numbers for stochastic update of the velocity.

495 They have a uniform distribution with the interval of $[0,1] . c_{1}$ and $c_{2}$ are the acceleration parameters that pull the particles towards $P_{i}^{\text {best }}$ and $P_{g}^{\text {best }} . c_{1}=c_{2}=2$ are recommended for most optimization problems according to Ozcan and Mohan (1999). We adopt the recommended settings. The swarm size $m$ also affects the PSO performance. So far, there are not exact rules selection of swarm size (Rezaee Jordehi and Jasni, 2013). Here we use the size $n$ of $\widehat{T I}$ to determine the swarm size $m$. We create $m=10 \times n$ particles in PSO population to enhance searching ability and running time.

Another important question is how to determine the optimal amount $n$ of $\widehat{T I}$. To specify $n$, we use a profile $\log$-likelihood approach from Zhu and Ghodsi (2006) and Honarkhah and Caers (2010). Specifically, we expect that the distance between training images and radar line data will decease as we visit more training images. The PSO optimized distance should decrease dramatically when the optimal $n$ TIs is visited, and then start flattening out. Hence, there will be an elbow point corresponding to the optimal number of TI. Based on the study in Honarkhah and Caers (2010), the elbow is found by maximizing profile log-likelihood. We find the optimal number of TIs using the following steps.

1. Run PSO to obtain the minimized distances $d i s_{n}$ with different $\widehat{T I}$ size $n$, where $n=1,2,3, \ldots, N-1$.

2. For every $n$, we define two samples of $\varphi_{1}=\left\{d i s_{1}, d i s_{2}, \ldots, d i s_{n}\right\}$ and $\varphi_{2}=\left\{d i s_{n+1}, d i s_{n+2}, \ldots, d i s_{N}\right\}$.

3. Calculate the log-likelihood $l_{n}(n)$ as: 


$$
\begin{aligned}
& l_{n}(n)=-n \log \left(\frac{1}{\sqrt{2 \pi \sigma^{2}}}\right) \sum_{i=1}^{n} \frac{\left(d i s_{i}-\mu_{1}\right)^{2}}{2 \sigma^{2}}+(n-N) \log \left(\frac{1}{\sqrt{2 \pi \sigma^{2}}}\right) \sum_{i=n+1}^{N} \frac{\left(d i s_{i}-\mu_{2}\right)^{2}}{2 \sigma^{2}} \\
& \sigma^{2}=\frac{(n-1) \sigma_{1}^{2}+(N-n-1) \sigma_{2}^{2}}{N-2}
\end{aligned}
$$

where $\mu_{1}, \mu_{2}$ are the means of $\varphi_{1}$ and $\varphi_{2}$, By contrast, $\sigma^{2}$ is the common scale variance. $\sigma_{1}, \sigma_{2}$ are the sample variances of $\varphi_{1}$ and $\varphi_{2}$.

4. Obtain the optimal (elbow) size $\hat{n}$ based on the empirical maximum value of $l_{n}(n)$.

We use the illustration case area A1 as an example to show how to select $\hat{n}$. Figure 20a plots the PSO distance function between A1 radar lines and TIs with varying TI numbers. We can observe a fast drop of the distance at the beginning, and the distance then drops slowly after $n=3$. To find out the exact elbow, we calculate the log-likelihood values and plot them in Figure 20b. Figure 20b clearly indicate that the optimal number of TI is 3.

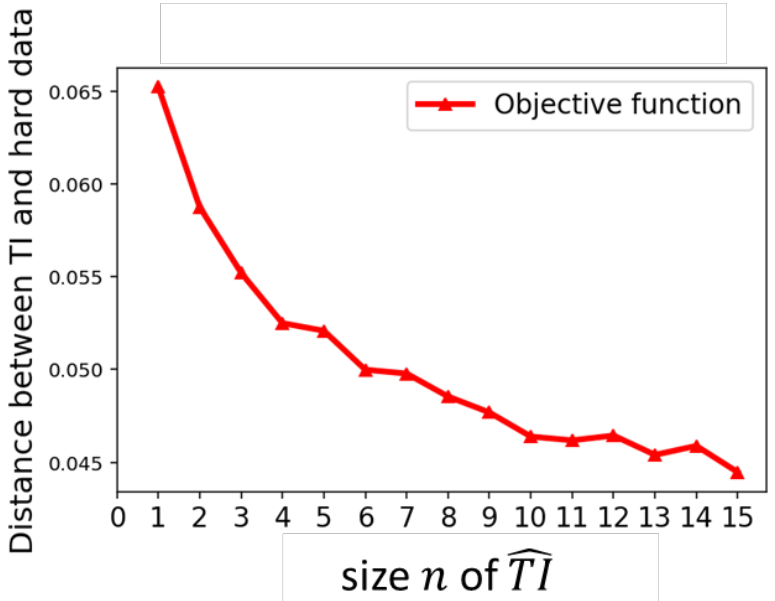

(a)

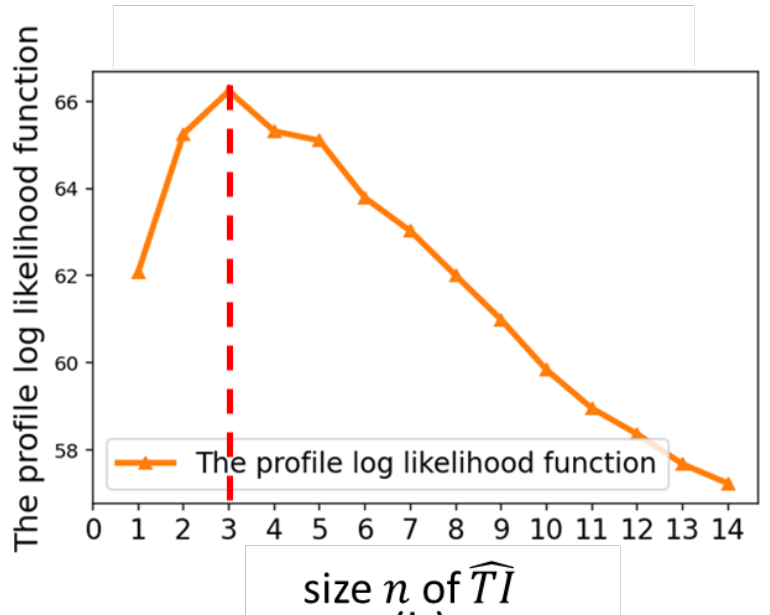

(b)

Figure 20. (a) PSO minimum distance vs. the swarm size n. (b) profile log-likelihood of curve (a), suggesting the optimal number of training images is 3 .

\section{Code and Data availability}

The subglacial topography training image database is publicly available at https://doi.org/10.5281/zenodo.5083715. The MPS

modeling codes and notebooks (MPS-BedMappingV1) used in this study are available at GitHub https://github.com/sdyinzhen/MPS-BedMappingV1, and archived at https://doi.org/10.5281/zenodo.5453360 (Yin et al, 2021). 


\section{Author contributions}

Zhen Yin and Chen Zuo (co-first authors): contributed the main concepts and methodology development; conducted the technical applications and drafted this paper.

Emma J. MacKie (second author): prepared the project data; performed the hydrological modeling; contributed critical insights during the research developments; drafted part of the paper.

Jef Caers: PI of the research project; provided overall supervision and funding to this project; contributed major and critical ideas to the research development and revised the manuscript.

\section{Competing interests}

The authors declare that they have no conflict of interests.

\section{References}

Allard, D., Comunian, A. and Renard, P.: Probability Aggregation Methods in Geoscience, Math. Geosci., 44(5), 545-581, doi:10.1007/s11004-012-9396-3, 2012.

Almeida, A. S. and Journel, A. G.: Joint simulation of multiple variables with a Markov-type coregionalization model, Math. Geol., 26(5), 565-588, doi:10.1007/BF02089242, 1994.

Arndt, J. E., Schenke, H. W., Jakobsson, M., Nitsche, F. O., Buys, G., Goleby, B., Rebesco, M., Bohoyo, F., Hong, J., Black, J., Greku, R., Udintsev, G., Barrios, F., Reynoso-Peralta, W., Taisei, M. and Wigley, R.: The International Bathymetric Chart of the Southern Ocean (IBCSO) Version 1.0-A new bathymetric compilation covering circumAntarctic waters, Geophys. Res. Lett., 40(12), 3111-3117, doi:https://doi.org/10.1002/grl.50413, 2013.

Blankenship, D. D., Morse, D. L., Finn, C. A., Bell, R. E., Peters, M. E., Kempf, S. D., Hodge, S. M., Studinger, M., Behrendt, J. C. and Brozena, J. M.: Geologic Controls on the Initiation of Rapid Basal Motion for West Antarctic Ice Streams: A Geophysical Perspective Including New Airborne Radar Sounding and Laser Altimetry Results, West Antarct. Ice Sheet Behav. Environ., 105-121, doi:https://doi.org/10.1029/AR077p0105, 2001.

Bruna, P.-O., Straubhaar, J., Prabhakaran, R., Bertotti, G., Bisdom, K., Mariethoz, G. and Meda, M.: A new methodology to train fracture network simulation using multiple-point statistics, Solid Earth, 10(2), 537-559, doi:10.5194/se-10-5372019, 2019.

Chugunova, T. L. and Hu, L. Y.: Multiple-Point Simulations Constrained by Continuous Auxiliary Data, Math. Geosci., 40(2), 133-146, doi:10.1007/s11004-007-9142-4, 2008.

Clarke, G. K. C., Berthier, E., Schoof, C. G. and Jarosch, A. H.: Neural Networks Applied to Estimating Subglacial Topography and Glacier Volume, J. Clim., 22(8), 2146-2160, doi:10.1175/2008JCLI2572.1, 2009. 
https://doi.org/10.5194/gmd-2021-297

Preprint. Discussion started: 14 September 2021

(C) Author(s) 2021. CC BY 4.0 License.
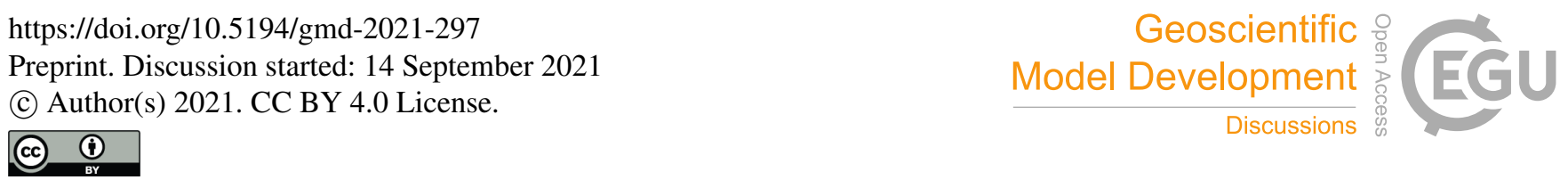

Le clec'h, S., Quiquet, A., Charbit, S., Dumas, C., Kageyama, M. and Ritz, C.: A rapidly converging initialisation method to simulate the present-day Greenland ice sheet using the GRISLI ice sheet model (version 1.3), Geosci. Model Dev., 12(6), 2481-2499, doi:10.5194/gmd-12-2481-2019, 2019.

Deutsch, C. V. and Journel, A. G.: GSLIB Geostatistical Software Library and User's Guide, Oxford University Press., 1998.

Dubuisson, M.-. and Jain, A. K.: A modified Hausdorff distance for object matching, in Proceedings of 12th International Conference on Pattern Recognition, vol. 1, pp. 566-568 vol.1., 1994.

Fouedjio, F.: Clustering of multivariate geostatistical data, WIREs Comput. Stat. , 12(5), e1510, doi:https://doi.org/10.1002/wics.1510, 2020.

Fretwell, P., Pritchard, H. D., Vaughan, D. G., Bamber, J. L., Barrand, N. E., Bell, R., Bianchi, C., Bingham, R. G., Blankenship, D. D., Casassa, G., Catania, G., Callens, D., Conway, H., Cook, A. J., Corr, H. F. J., Damaske, D., Damm, V., Ferraccioli, F., Forsberg, R., Fujita, S., Gim, Y., Gogineni, P., Griggs, J. A., Hindmarsh, R. C. A., Holmlund, P., Holt, J. W., Jacobel, R. W., Jenkins, A., Jokat, W., Jordan, T., King, E. C., Kohler, J., Krabill, W., Riger-Kusk, M., Langley, K. A., Leitchenkov, G., Leuschen, C., Luyendyk, B. P., Matsuoka, K., Mouginot, J., Nitsche, F. O., Nogi, Y., Nost, O. A., Popov, S. V., Rignot, E., Rippin, D. M., Rivera, A., Roberts, J., Ross, N., Siegert, M. J., Smith, A. M., Steinhage, D., Studinger, M., Sun, B., Tinto, B. K., Welch, B. C., Wilson, D., Young, D. A., Xiangbin, C. and Zirizzotti, A.: Bedmap2: improved ice bed, surface and thickness datasets for Antarctica, Cryosph., 7(1), 375-393, doi:10.5194/tc-7-375-2013, 2013.

Goff, J. A., Powell, E. M., Young, D. A. and Blankenship, D. D.: Conditional simulation of Thwaites Glacier (Antarctica) bed topography for flow models: Incorporating inhomogeneous statistics and channelized morphology, J. Glaciol., 60(222), 635-646, doi:DOI: 10.3189/2014JoG13J200, 2014.

580 Gogineni, P.: CReSIS radar depth sounder data. Center for Remote Sensing of Ice Sheets, Lawrence, KS, 2012.

Gravey, M. and Mariethoz, G.: QuickSampling v1.0: a robust and simplified pixel-based multiple-point simulation approach, Geosci. Model Dev., 13(6), 2611-2630, doi:10.5194/gmd-13-2611-2020, 2020.

Greene, C. A., Gwyther, D. E. and Blankenship, D. D.: Antarctic Mapping Tools for Matlab, Comput. Geosci., 104, 151-157, doi:https://doi.org/10.1016/j.cageo.2016.08.003, 2017.

Han, J., Kamber, M. and Pei, J.: 3 - Data Preprocessing, in The Morgan Kaufmann Series in Data Management Systems, edited by J. Han, M. Kamber, and J. B. T.-D. M. (Third E. Pei, pp. 83-124, Morgan Kaufmann, Boston., 2012.

Han, W., Yang, P., Ren, H. and Sun, J.: Comparison study of several kinds of inertia weights for PSO, in 2010 IEEE International Conference on Progress in Informatics and Computing, vol. 1, pp. 280-284., 2010.

Herzfeld, U. C., Eriksson, M. G. and Holmlund, P.: On the influence of kriging parameters on the cartographic output-A study in mapping subglacial topography, Math. Geol., 25(7), 881-900, doi:10.1007/BF00891049, 1993.

Hoffimann, J., Scheidt, C., Barfod, A. and Caers, J.: Stochastic simulation by image quilting of process-based geological models, Comput. Geosci., 106, 18-32, doi:https://doi.org/10.1016/j.cageo.2017.05.012, 2017a.

Hoffimann, J., Scheidt, C., Barfod, A. and Caers, J.: Stochastic simulation by image quilting of process-based geological models, Comput. Geosci., 106, 18-32, doi:https://doi.org/10.1016/j.cageo.2017.05.012, 2017b.

Hoffimann, J., Bufe, A. and Caers, J.: Morphodynamic Analysis and Statistical Synthesis of Geomorphic Data: Application to a Flume Experiment, J. Geophys. Res. Earth Surf., 124(11), 2561-2578, doi:10.1029/2019JF005245, 2019.

Holschuh, N., Christianson, K., Paden, J., Alley, R. B. and Anandakrishnan, S.: Linking postglacial landscapes to glacier dynamics using swath radar at Thwaites Glacier, Antarctica, Geology, 48(3), 268-272, doi:10.1130/G46772.1, 2020.

Holt, J. W., Blankenship, D. D., Morse, D. L., Young, D. A., Peters, M. E., Kempf, S. D., Richter, T. G., Vaughan, D. G. and Corr, H. F. J.: New boundary conditions for the West Antarctic Ice Sheet: Subglacial topography of the Thwaites and Smith glacier catchments, Geophys. Res. Lett., 33(9), doi:https://doi.org/10.1029/2005GL025561, 2006. 
https://doi.org/10.5194/gmd-2021-297

Preprint. Discussion started: 14 September 2021

(C) Author(s) 2021. CC BY 4.0 License.

Honarkhah, M. and Caers, J.: Stochastic Simulation of Patterns Using Distance-Based Pattern Modeling, Math. Geosci., 42(5), 487-517, doi:10.1007/s11004-010-9276-7, 2010.

Honarkhah, M. and Caers, J.: Direct Pattern-Based Simulation of Non-stationary Geostatistical Models, Math. Geosci., 44(6), 651-672, doi:10.1007/s11004-012-9413-6, 2012.

Howat, I. M., Porter, C., Smith, B. E., Noh, M.-J. and Morin, P.: The Reference Elevation Model of Antarctica, Cryosph., 13(2), 665-674, doi:10.5194/tc-13-665-2019, 2019.

Huss, M. and Farinotti, D.: Distributed ice thickness and volume of all glaciers around the globe, J. Geophys. Res. Earth Surf., 117(F4), doi:https://doi.org/10.1029/2012JF002523, 2012.

Huttenlocher, D. P., Klanderman, G. A. and Rucklidge, W. J.: Comparing images using the Hausdorff distance, IEEE Trans. Pattern Anal. Mach. Intell., 15(9), 850-863, doi:10.1109/34.232073, 1993.

Joughin, I., Smith, B. E. and Medley, B.: Marine Ice Sheet Collapse Potentially Under Way for the Thwaites Glacier Basin, West Antarctica, Science (80-. )., 344(6185), 735 LP - 738, doi:10.1126/science.1249055, 2014.

Journel, A. and Zhang, T.: The Necessity of a Multiple-Point Prior Model, Math. Geol., 38(5), 591-610, doi:10.1007/s11004006-9031-2, 2006.

King, E. C., Hindmarsh, R. C. A. and Stokes, C. R.: Formation of mega-scale glacial lineations observed beneath a West Antarctic ice stream, Nat. Geosci., 2(8), 585-588, doi:10.1038/ngeo581, 2009.

Laloy, E., Hérault, R., Jacques, D. and Linde, N.: Training-Image Based Geostatistical Inversion Using a Spatial Generative Adversarial Neural Network, Water Resour. Res., 54(1), 381-406, doi:10.1002/2017WR022148, 2018.

MacKie, E. J., Schroeder, D. M., Caers, J., Siegfried, M. R. and Scheidt, C.: Antarctic Topographic Realizations and Geostatistical Modeling Used to Map Subglacial Lakes, J. Geophys. Res. Earth Surf., 125(3), e2019JF005420, doi:https://doi.org/10.1029/2019JF005420, 2020.

MacKie, E. J., Schroeder, D. M., Zuo, C., Yin, Z. and Caers, J.: Stochastic modeling of subglacial topography exposes uncertainty in water routing at Jakobshavn Glacier, J. Glaciol., 67(261), 75-83, doi:DOI: 10.1017/jog.2020.84, 2021.

Margold, M., Stokes, C. R. and Clark, C. D.: Ice streams in the Laurentide Ice Sheet: Identification, characteristics and comparison to modern ice sheets, Earth-Science Rev., 143, 117-146, doi:https://doi.org/10.1016/j.earscirev.2015.01.011, 2015.

Mariethoz, G.: When Should We Use Multiple-Point Geostatistics? BT - Handbook of Mathematical Geosciences: Fifty Years of IAMG, edited by B. S. Daya Sagar, Q. Cheng, and F. Agterberg, pp. 645-653, Springer International Publishing, Cham., 2018.

Mariethoz, G. and Renard, P.: Reconstruction of Incomplete Data Sets or Images Using Direct Sampling, Math. Geosci., 42(3), 245-268, doi:10.1007/s11004-010-9270-0, 2010.

Mariethoz, G., Renard, P. and Straubhaar, J.: The Direct Sampling method to perform multiple-point geostatistical simulations, Water Resour. Res., 46(11), doi:https://doi.org/10.1029/2008WR007621, 2010a.

Mariethoz, G., Renard, P. and Straubhaar, J.: The Direct Sampling method to perform multiple-point geostatistical simulations, Water Resour. Res., 46(11), doi:10.1029/2008WR007621, 2010b.

Mariethoz, G., McCabe, M. F. and Renard, P.: Spatiotemporal reconstruction of gaps in multivariate fields using the direct sampling approach, Water Resour. Res., 48(10), doi:https://doi.org/10.1029/2012WR012115, 2012.

Mariethoz, P. G. and Caers, J.: Multiple-point Geostatistics: Stochastic Modeling with Training Images, Wiley. [online] Available from: https://books.google.com/books?id=_DcBAAAQBAJ, 2014.

Matheron, G.: Principles of geostatistics, Econ. Geol., 58(8), 1246-1266, doi:10.2113/gsecongeo.58.8.1246, 1963. 
https://doi.org/10.5194/gmd-2021-297

Preprint. Discussion started: 14 September 2021

(c) Author(s) 2021. CC BY 4.0 License.
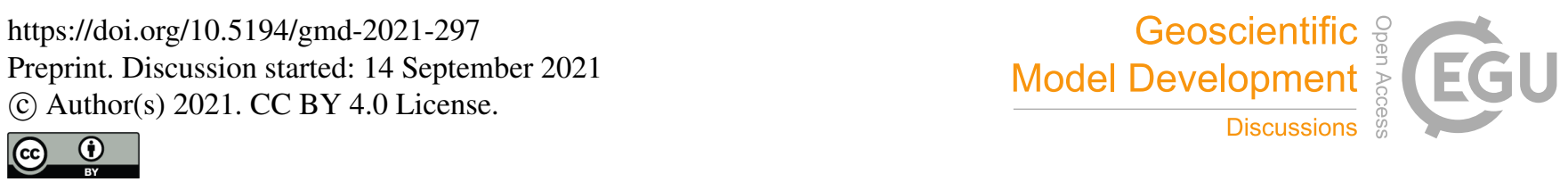

Meerschman, E., Pirot, G., Mariethoz, G., Straubhaar, J., Van Meirvenne, M. and Renard, P.: A practical guide to performing multiple-point statistical simulations with the Direct Sampling algorithm, Comput. Geosci., 52, 307-324, doi:https://doi.org/10.1016/j.cageo.2012.09.019, 2013.

Mo, S., Zabaras, N., Shi, X. and Wu, J.: Integration of Adversarial Autoencoders With Residual Dense Convolutional Networks for Estimation of Non-Gaussian Hydraulic Conductivities, Water Resour. Res., 56(2), e2019WR026082, doi:https://doi.org/10.1029/2019WR026082, 2020.

Morlighem, M., Williams, C. N., Rignot, E., An, L., Arndt, J. E., Bamber, J. L., Catania, G., Chauché, N., Dowdeswell, J. A., Dorschel, B., Fenty, I., Hogan, K., Howat, I., Hubbard, A., Jakobsson, M., Jordan, T. M., Kjeldsen, K. K., Millan, R., Mayer, L., Mouginot, J., Noël, B. P. Y., O’Cofaigh, C., Palmer, S., Rysgaard, S., Seroussi, H., Siegert, M. J., Slabon, P., Straneo, F., van den Broeke, M. R., Weinrebe, W., Wood, M. and Zinglersen, K. B.: BedMachine v3: Complete Bed Topography and Ocean Bathymetry Mapping of Greenland From Multibeam Echo Sounding Combined With Mass Conservation, Geophys. Res. Lett., 44(21), 11,11-51,61, doi:https://doi.org/10.1002/2017GL074954, 2017.

Morlighem, M., Rignot, E., Binder, T., Blankenship, D., Drews, R., Eagles, G., Eisen, O., Ferraccioli, F., Forsberg, R., Fretwell, P., Goel, V., Greenbaum, J. S., Gudmundsson, H., Guo, J., Helm, V., Hofstede, C., Howat, I., Humbert, A., Jokat, W., Karlsson, N. B., Lee, W. S., Matsuoka, K., Millan, R., Mouginot, J., Paden, J., Pattyn, F., Roberts, J., Rosier, S., Ruppel, A., Seroussi, H., Smith, E. C., Steinhage, D., Sun, B., Broeke, M. R. van den, Ommen, T. D. van, Wessem, M. van and Young, D. A.: Deep glacial troughs and stabilizing ridges unveiled beneath the margins of the Antarctic ice sheet, Nat. Geosci., 13(2), 132-137, doi:10.1038/s41561-019-0510-8, 2020.

Oriani, F., Straubhaar, J., Renard, P. and Mariethoz, G.: Simulation of rainfall time series from different climatic regions using the direct sampling technique, Hydrol. Earth Syst. Sci., 18(8), 3015-3031, doi:10.5194/hess-18-3015-2014, 2014.

Ozcan, E. and Mohan, C. K.: Particle swarm optimization: surfing the waves, in Proceedings of the 1999 Congress on Evolutionary Computation-CEC99 (Cat. No. 99TH8406), vol. 3, pp. 1939-1944 Vol. 3., 1999.

Porter, C., Morin, P., Howat, I., Noh, M.-J., Bates, B., Peterman, K., Keesey, S., Schlenk, M., Gardiner, J., Tomko, K., Willis, M., Kelleher, C., Cloutier, M., Husby, E., Foga, S., Nakamura, H., Platson, M., Wethington Jr., M., Williamson, C., Bauer, G., Enos, J., Arnold, G., Kramer, W., Becker, P., Doshi, A., D’Souza, C., Cummens, P., Laurier, F. and Bojesen, M. A.-N. S. F. A.-N. S. F.: ArcticDEM, , doi:doi:10.7910/DVN/OHHUKH, 2018.

Pyrcz, M. J. and White, C. D.: Uncertainty in reservoir modeling, Interpretation, 3(2), SQ7-SQ19, doi:10.1190/INT-20140126.1, 2015.

Rezaee Jordehi, A. and Jasni, J.: Parameter selection in particle swarm optimisation: a survey, J. Exp. Theor. Artif. Intell., 25(4), 527-542, doi:10.1080/0952813X.2013.782348, 2013.

Rignot, E., Mouginot, J., Scheuchl, B., van den Broeke, M., van Wessem, M. J. and Morlighem, M.: Four decades of Antarctic Ice Sheet mass balance from 1979-2017, Proc. Natl. Acad. Sci., 116(4), 1095 LP - 1103, doi:10.1073/pnas.1812883116, 2019.

Romary, T., Ors, F., Rivoirard, J. and Deraisme, J.: Unsupervised classification of multivariate geostatistical data: Two algorithms, Comput. Geosci., 85, 96-103, doi:https://doi.org/10.1016/j.cageo.2015.05.019, 2015.

Scheidt, C., Li, L. and Caers, J.: Quantifying Uncertainty in Subsurface Systems, Wiley., 2018.

Schmidt, A. M. and O'Hagan, A.: Bayesian inference for non-stationary spatial covariance structure via spatial deformations, J. R. Stat. Soc. Ser. B (Statistical Methodol., 65(3), 743-758, doi:https://doi.org/10.1111/1467-9868.00413, 2003.

Schwanghart, W. and Scherler, D.: Short Communication: TopoToolbox 2 - MATLAB-based software for topographic analysis and modeling in Earth surface sciences, Earth Surf. Dyn., 2(1), 1-7, doi:10.5194/esurf-2-1-2014, 2014.

Seroussi, H., Nakayama, Y., Larour, E., Menemenlis, D., Morlighem, M., Rignot, E. and Khazendar, A.: Continued retreat of Thwaites Glacier, West Antarctica, controlled by bed topography and ocean circulation, Geophys. Res. Lett., 44(12), 6191-6199, doi:https://doi.org/10.1002/2017GL072910, 2017. 
https://doi.org/10.5194/gmd-2021-297

Preprint. Discussion started: 14 September 2021

(C) Author(s) 2021. CC BY 4.0 License.

Shreve, R. L.: Movement of Water in Glaciers, J. Glaciol., 11(62), 205-214, doi:DOI: 10.3189/S002214300002219X, 1972.

Silverman, B. W.: Using Kernel Density Estimates to Investigate Multimodality, J. R. Stat. Soc. Ser. B, 43(1), 97-99, doi:https://doi.org/10.1111/j.2517-6161.1981.tb01155.x, 1981.

Smith, B. E., Gourmelen, N., Huth, A. and Joughin, I.: Connected subglacial lake drainage beneath Thwaites Glacier, West Antarctica, Cryosph., 11(1), 451-467, doi:10.5194/tc-11-451-2017, 2017.

Spagnolo, M., Bartholomaus, T. C., Clark, C. D., Stokes, C. R., Atkinson, N., Dowdeswell, J. A., Ely, J. C., Graham, A. G. C., Hogan, K. A., King, E. C., Larter, R. D., Livingstone, S. J. and Pritchard, H. D.: The periodic topography of ice stream beds: Insights from the Fourier spectra of mega-scale glacial lineations, J. Geophys. Res. Earth Surf., 122(7), 1355-1373, doi:https://doi.org/10.1002/2016JF004154, 2017.

Srivastava, M. R.: The Origins of the Multiple-Point Statistics (MPS) Algorithm BT - Handbook of Mathematical Geosciences: Fifty Years of IAMG, edited by B. S. Daya Sagar, Q. Cheng, and F. Agterberg, pp. 655-672, Springer International Publishing, Cham., 2018.

Stearns, L. A., Smith, B. E. and Hamilton, G. S.: Increased flow speed on a large East Antarctic outlet glacier caused by subglacial floods, Nat. Geosci., 1(12), 827-831, doi:10.1038/ngeo356, 2008.

Strebelle, S.: Conditional Simulation of Complex Geological Structures Using Multiple-Point Statistics, Math. Geol., 34(1), 1-21, doi:10.1023/A:1014009426274, 2002.

Strebelle, S. B. and Journel, A. G.: Reservoir Modeling Using Multiple-Point Statistics, SPE Annu. Tech. Conf. Exhib., 11, doi:10.2118/71324-MS, 2001.

Tahmasebi, P.: Multiple Point Statistics: A Review BT - Handbook of Mathematical Geosciences: Fifty Years of IAMG, edited by B. S. Daya Sagar, Q. Cheng, and F. Agterberg, pp. 613-643, Springer International Publishing, Cham., 2018.

Vaughan, D. G., Corr, H. F. J., Ferraccioli, F., Frearson, N., O’Hare, A., Mach, D., Holt, J. W., Blankenship, D. D., Morse, D. L. and Young, D. A.: New boundary conditions for the West Antarctic ice sheet: Subglacial topography beneath Pine Island Glacier, Geophys. Res. Lett., 33(9), doi:https://doi.org/10.1029/2005GL025588, 2006.

Williams, C. K. I. and Rasmussen, C. E.: Gaussian processes for regression, in Advances in Neural Information Processing Systems 8, edited by D. S. Touretzky, M. C. Mozer, and M. E. Hasselmo, MIT. [online] Available from: https://publications.aston.ac.uk/id/eprint/651/, 1996.

Wu, J., Boucher, A. and Zhang, T.: A SGeMS code for pattern simulation of continuous and categorical variables: FILTERSIM, Comput. Geosci., 34(12), 1863-1876, doi:https://doi.org/10.1016/j.cageo.2007.08.008, 2008.

Yin, G., Mariethoz, G. and McCabe, M. F.: Gap-Filling of Landsat 7 Imagery Using the Direct Sampling Method, Remote Sens. , 9(1), doi:10.3390/rs9010012, 2017.

Young, D. A., Schroeder, D. M., Blankenship, D. D., Kempf, S. D. and Quartini, E.: The distribution of basal water between Antarctic subglacial lakes from radar sounding, Philos. Trans. R. Soc. A Math. Phys. Eng. Sci., 374(2059), 20140297, doi:10.1098/rsta.2014.0297, 2016.

Zakeri, F. and Mariethoz, G.: A review of geostatistical simulation models applied to satellite remote sensing: Methods and applications, Remote Sens. Environ., 259, 112381, doi:https://doi.org/10.1016/j.rse.2021.112381, 2021.

Zhou, H., Gómez-Hernández, J. J. and Li, L.: Inverse methods in hydrogeology: Evolution and recent trends, Adv. Water Resour., 63, 22-37, doi:10.1016/J.ADVWATRES.2013.10.014, 2014.

Zuo, C., Yin, Z., Pan, Z., MacKie, E. J. and Caers, J.: A Tree-Based Direct Sampling Method for Stochastic Surface and Subsurface Hydrological Modeling, Water Resour. Res., 56(2), e2019WR026130, doi:10.1029/2019WR026130, 2020 . 